$i=i=1$

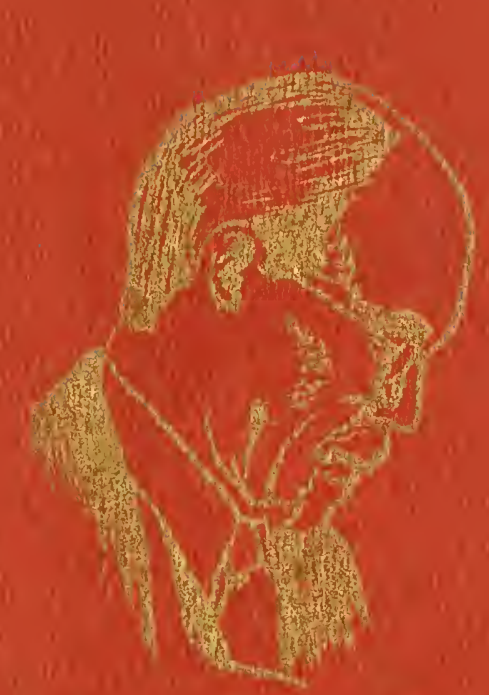

- Jim Jaoub Abets , in 0 .

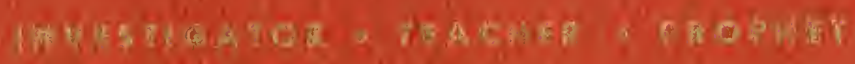
1897.1038 


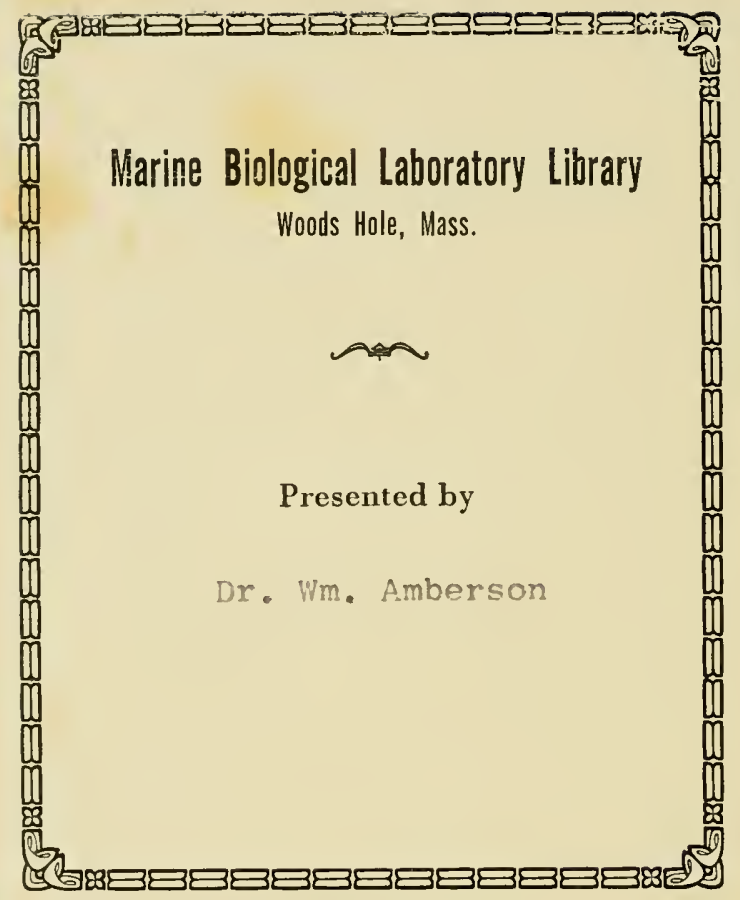







. 


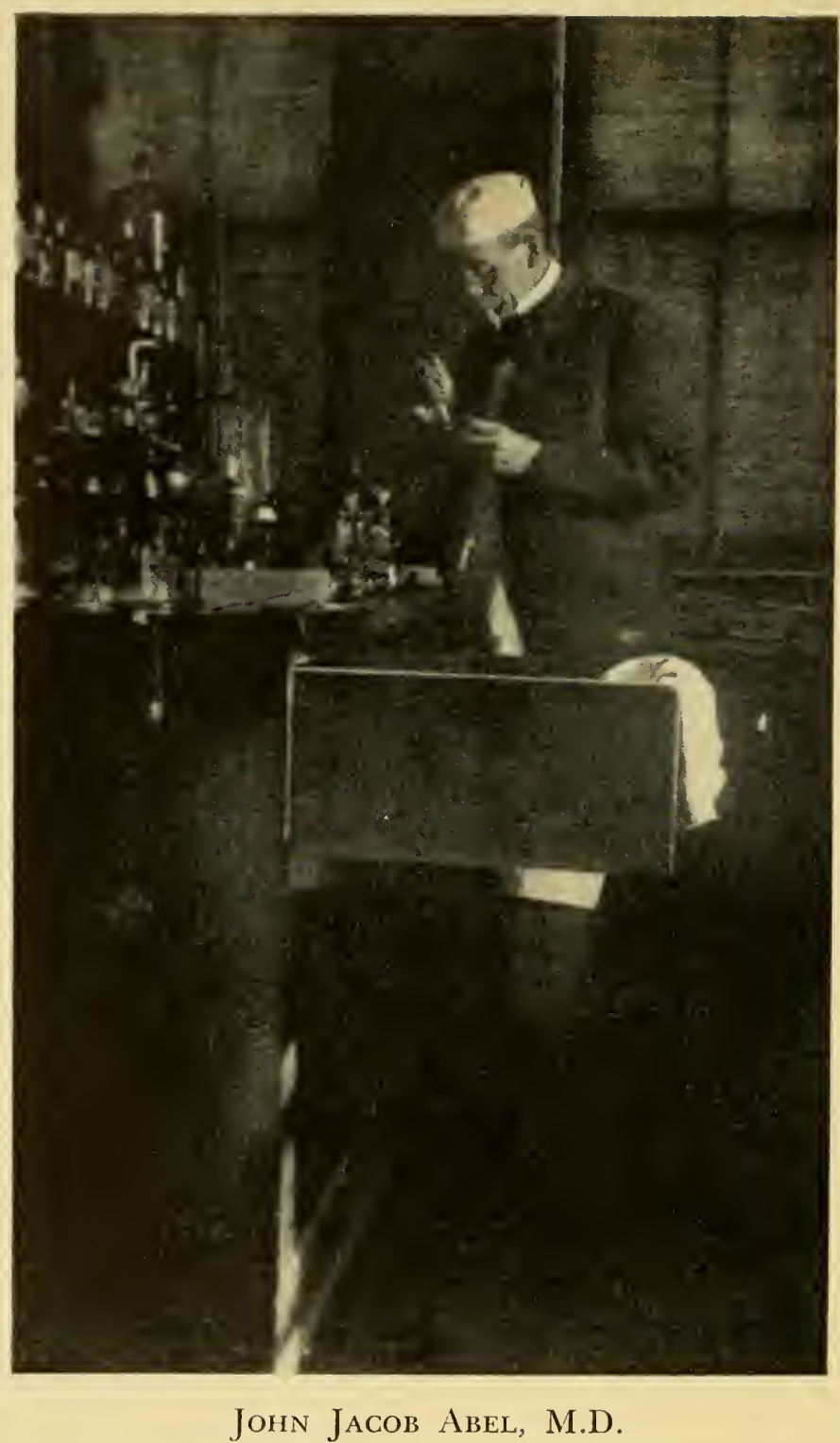

.... in his laboratory in the old Physiology Building at Hopkins 
John Jacob Abel, M.D. 


\title{
A Collection of
}

Papers by and about

\author{
The Father of \\ American
}

Pharmacology

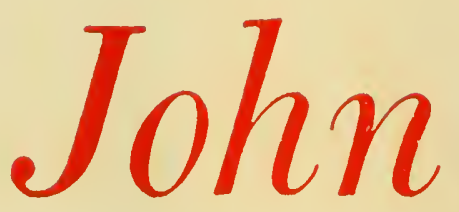

IN VES T I G A T OR •






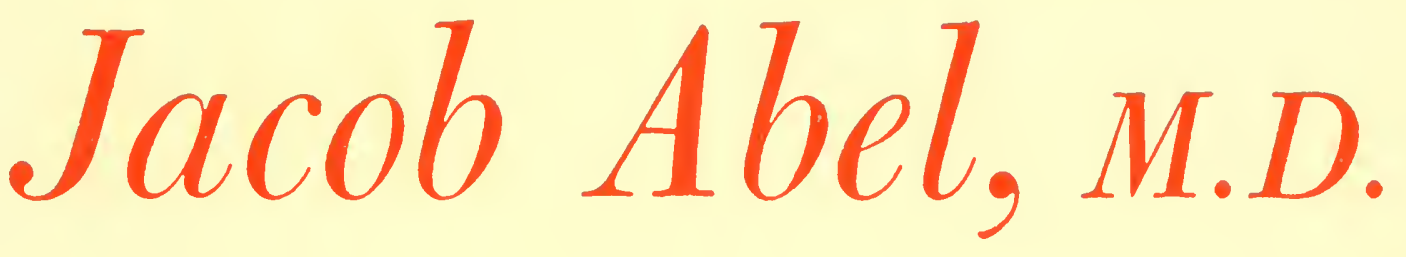

TEACHER・PROPHET • 1857-1938

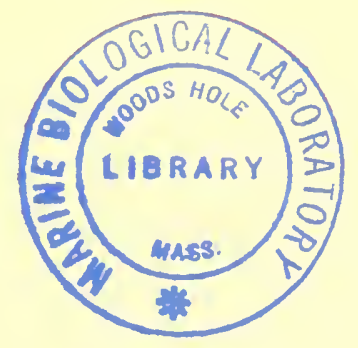

T H E W I L L I A M S \& W I L K I N S C O M P A N Y Baltimore, 1957 
composed and printed by

WAVERLy Press, Inc.

Mt. Royal \& Guilford Aves.

Baltimore 2, Md., U.S.A. 


\section{Publishers Foreword}

This limited edition of a collection of papers by and about John Jacob Abel is, like many of Dr. Abel's own endeavors, a labor of love. It has been prepared and published as a memorial to Dr. Abel on the occasion of the one-hundredth anniversary of his birth. It is intended for distribution to members of the American Society for Pharmacology and Experimental Therapeutics, to others who have been associated with Dr. Abel and his work, and to friends of ours who will, we think, be interested.

The brief recitation of a bit of history seems requisite for two reasons of quite unequal importance. The first and least important, is to justify our association with this enterprise. The second is to exhibit a facet in the career of Dr. Abel that could easily be quite unknown to many.

In 1908 or 1909, Dr. Abel conceived the idea of a journal to serve as means of communication in the field of pharmacology. In his casting about for means of bringing the idea to practical result, he encountered Edward B. Passano, then proprietor of a printing concern called Williams \& Wilkins Co. That company had, a few years earlier, begun to specialize in the printing of the literature of science; but it had done no publishing-i.e., it had not assumed the risks of an entrepreneur.

Dr. Abel convinced Mr. Passano that American facilities for the communication of science results were sadly lacking, and persuaded him that such a field of endeavor could be most rewarding and might one day be profitable.

The practical result was that the printing company began, in 1909, to publish The Journal of Pharmacology and Experimental Therapeutics, Dr. Abel being its founder and editor (1909-1932), and has continued to do so ever since. A concomitant result was the inception during the next decade, under the aegis of Williams \& Wilkins, of a number of new American journals in science. The publishing venture was extended to books in 1920, and by 1925 it appeared to be of sufficient volume and extent to justify separate corporate existence. The old name, with a slight change, was retained for the publishing business; the manufacturing or printing branch took the style, Waverly Press, Inc. 
Thus Dr. Abel was instrumental in bringing a publishing house into existence, one that has not been without importance to American science; at least it did pioneer in a field which, in the early years of the century, was anything but attractive to business entrepreneurs. To be sure, Dr. Abel did not work alone. But without his interposition and his inspiration, nothing would have been done. Many others must have deplored the lack of publishing facilities as he did. But he had the percipience to look a little more clearly into the future and the confidence that enabled him to make others share his vision.

Probably Dr. Abel himself would not have counted the establishment of a publishing business among his achievements. Yet it is certain that he planted the seed from which one grew and equally certain that he read the future correctly.

The Williams \& Wilkins Company WAVERly Press, Inc. 


\section{Contents}

Abel the Prophet. E. K. Marshall, Jr.............. I

John Jacob Abel-A Portrait. Paul D. Lamson ............ 8

On the Blood-Pressure-Raising Constituent of the Suprarenal Capsule. John J. Abel and Albert C. Crawford ........... 43

On the Teaching of Pharmacology, Materia Medica, and Therapeutics in our Medical Schools. JoHn J. ABEL.

On the Removal of Diffusible Substances from the Circulating Blood by Means of Dialysis. John J. Abel, L. G. Rowntree, And B. B. Turner ........................ 73

Crystalline Insulin. JoHn J. ABeL 76 


\section{Acknowledgment}

Grateful acknowledgement is made to the authors and original publishers of the articles in this book. Without their permissions to reprint so extensively from their copyrighted publications this tribute to Dr. Abel would not have been possible.

Abel the Prophet. E. K. Marshall, Jr.

Reprinted from "The Johns Hopkins Magazine," Volume I, 1950.

John Jacob Abel-A Portrait. Paul D. Lamson.

Reprinted from "Bulletin of the Johns Hopkins Hospital," Volume 68, 1941.

On the Blood-Pressure-Raising Constituent of the Suprarenal Capsule. John J. Abel and Albert C. Crawford.

Reprinted from "Bulletin of The Johns Hopkins Hospital," Volume 8, 1897.

On the Teaching of Pharmacology, Materia Medica, and Therapeutics in our Medical Schools. John J. Abel.

Reprinted from "The Philadelphia Medical Journal," special number on Medical Education, September 1, 1900.

On the Removal of Diffusible Substances from the Circulating Blood by Means of Dialysis. John J. Abel, L. G. Rowntree and B. B. Turner.

Reprinted from "Transactions of the Association of American Physicians," Volume 28, 1913.

Crystalline Insulin. John J. Abel.

Reprinted from "Proceedings of the National Academy of Sciences," Volume 12, 1926. 


\section{Abel the Prophet}

E. K. MARSHALL, JR., M.D.

I

I THE fall of 1936, the sulfa drugs were just beginning to be used in this country. Within a decade, better sulfa drugs were introduced and less toxic and more effective remedies like penicillin and streptomycin cured many forms of infectious disease. However, in that autumn of 1936, I knew that few appreciated that the introduction of the sulfa drugs would completely revolutionize the treatment and importance of infectious disease, that they would make Ehrlich's dream of a harmless magic bullet with which to cure disease almost come true.

On Christmas Eve of that year, I called on my old teacher, colleague, and friend, John J. Abel, and found him very busy in his laboratory. Having known him for over a quarter of a century, I realized that the time was not ripe to sit for a long chat, and without removing overcoat, I sat down and talked with him for the cluration of one cigarette.

When I arose, the old gentleman in a fatherly way put his arm around my shoulder and very politely piloted me to the door. When we arrived there, he stopped for a moment and, more as a gesture of politeness than anything else, he asked me what I was doing now. I told him I had been very busy all fall with the pharmacology of the new antibacterial remedy, sulfanilamide. He said, "That's fine," then jerked up and with a characteristic lift of the eyebrows, "What's this all about?"

He asked a couple of searching questions and then led me back into the room. "Sit down, take off that coat, smoke a cigarette, and tell me all about it."

"Oh, but you're very busy, Professor. I'll come over some other time," I replied.

"Never too busy to hear about things like this, my boy," he said.

For a half hour or more, I told him what I knew about this new development in medicine. He asked some very pertinent questions, and then raised his head and with a faraway look said, "My God, Marshall, wouldn't Paul Ehrlich turn over in his grave?

This seventy-nine-year-old scientist saw at once the great signifi- 
cance of what had happened and had such a vision of the future that the miracles of the next decade might not have surprised him if he had lived to see them. This breadth of vision in foreseeing important developments of medicine was one of the qualities which was responsible for much of Abel's success and greatness.

John Jacob Abel belonged to that small group of men who made up the first faculty of the Johns Hopkins School of Medicine, and, in addition, was one of the pioneers who helped build up scientific medicine in America to the high place which it now occupies in the world. This is not the place to review Abel's contributions to science, which covered many subjects during a period no less than half a century. However, I shall try to point out many instances of his prophetic vision in regard to the future developments which were to take place in medicine.

The life of this first professor of pharmacology in the Johns Hopkins University began on a farm near Cleveland, Ohio, on the nineteenth of May, 1857, and ended in Baltimore on May 26, 1938, after a long career in American experimental medicine. His family came from the Rhine Valley of the Palatinate. He had no scientific forebears on either side. There is reason to believe that he owed his college education to his initiative

He received his Ph.B. degree from the University of Michigan in 1883, but had an interim of three years in his college course, during which he served as principal of a high school at La Porte, Indiana, where he taught Latin, mathematics, physics, and chemistry. Abel must have looked back on these years with satisfaction, for it was in La Porte that he met a teacher in his school, whom he once described as a "very sweet, mild little lady with a great deal of force." This lady, Mary Hinman, became his wife and was his companion for fiftyfive years. She stood by his side through many tribulations and encouraged her husband to acquire a broad medical and scientific education. There can be no doubt that Abel's happy family life was a potent factor in his scientific career.

After graduation, Abel set his course definitely for scientific medicine as his life's work. Two things which he did at that time indicate his ability to see what scientific medicine was to be like in the future. He submitted himself to a prolonged, broad, fundamental training, which consisted of a year with Newell Martin in physiology at the Johns Hopkins and then seven years with some leading teachers in the inedical schools of Europe. He thus acquired not only a medical 
degree, but a broad scientific education, and was prepared for scientific medicine in a way which in this country was only recognized as the correct one some thirty or forty years later.

Also, there can be little doubt that at this time Abel had a clear vision of what a tremendous role chemistry was to play in the future of scientific medicine. Irrespective of the expense, which he could ill afford, he determined to be prepared for this coming development. While in Europe in 1889, he frequently mentions in his letters the need of medical chemistry in the hospitals in this country and wants to come back to the States with some entirely "new line" of work as well as to get "ready for the twentieth century." Although many of his colleagues at that time thought his ideas absurd and visionary, everyone now realizes how justified this vision of his in regard to chemistry in medicine was.

Very soon after coming to the Hopkins in 1893, his interest developed in the glands of internal secretion (the endocrine glands) and indeed in the isolation of their active principles or hormones. He first tackled the thyroid gland and was busily engaged on this project when news of Baumann's work on the iodine-containing iodothyroglobulin came out. He stopped the thyroid work, but soon became interested in the hormone of the adrenal medulla, which had a remarkable blood-pressure-raising action.

When one considers the tremendous importance in medicine of this field of the endocrines (or hormones) at the present time, one can only think of Abel's early interest as prophetic. It is now well recognized that the key to many problems connected with each endocrine gland is to be found in the isolation of the pure active principle. That he early appreciated the importance of such contributions is shown by the following sentence in one of his addresses: "The actual finding of definite and specific chemical principles in the organs of internal secretion has in each case an importance in the way of explaining and correlating a large number of disconnected facts, only to be likened to the discovery of the etiological cause of an infectious disease." He was fond of emphasizing the importance of the powerful drugs present in the human body in the aphorism, "We are walking drug stores."

To return to Abel's first published research on the hormones, it is well known that in 1897, he isolated the active principle or hormone of the adrenal medulla in the form of a benzoyl derivative. This was the first instance of the isolation of a hormone of any endocrine gland. Later, the pure substance was isolated without the benzoyl radical. 
This substance has been called epinephrine or adrenaline and has been used in medicine for the past half century.

Scarcely a night passes in the accident room of any large hospital that patients suffering from asthma are not given an injection of epinephrine, which gives dramatic relief to these sufferers in the course of a few minutes. Many individuals covered with urticaria (hives) obtain complete relief from this troublesome condition by an injection of epinephrine. Due to the fact that this substance causes a marked constriction of blood vessels, it is used thousands of times every day in connection with local anesthetics. Every time a tooth is extracted, every time a minor surgical operation is performed, this substance is used in connection with the local anesthetic.

Opinions may differ as to how much credit should be given to Abel as the one responsible for the isolation of the first pure hormone. It is quite true that he did not obtain the hormone of the adrenal medulla as such but only in the form of a derivative, and it is equally evident that during the decade in which he was engaged in this problem, he fell into many pitfalls and made mistakes. It is now well known that the so-called pure hormone obtained from the adrenals is a mixture of two substances, epinephrine and nor-epinephrine. Be that as it may no one can detract from the importance of Abel's pioneering work in making available this valuable medicinal for research and therapy.

Shortly after the hormone insulin, which has revolutionized the treatment and progress of diabetes, was discovered, Abel interested himself in an attempt to obtain the hormone in chemically pure crystalline form. This he succeeded in doing in 1926, in spite of his sixty-nine years and his quaint and antiquated methods of chemical procedure. This was the first isolation in pure crystalline form of a hormone which must be considered as a protein.

Abel's announcement of the crystallization of insulin was received with skepticism by many chemists as a final proof of the isolation of the pure hormone. The criticism was made that the highly potent true hormone was adsorbed on a crystalline protein. But all criticisms were finally met and Abel's great achievement of the chemical isolation of insulin in pure crystalline form was soon completely established. It is amusing to recall that for many months after the preparation of the crystals, Abel himself was unable to repeat the performance. He never, however, lost faith. Ultimately, he found the answer and crystalline insulin is now commercially prepared.

This great optimism in regard to the outcome of his researches is 
well illustrated by incidents which occurred during his efforts to isolate in pure form the hormone of the posterior pituitary gland. An assistant who was testing Abel's preparations for pharmacological activity tells me that after he had tested dozens of preparations and found them all inactive, Abel would come to him with a new one and confidently say, "I've got it this time." After an evening of testing, the assistant informed Abel the next morning that the preparation was completely inactive and was greeted, "It's probably left in the mother liquor. We'll be sure to get it next time." This abiding faith, optimism, and enthusiasm in spite of great difficulties and disappointments marked Abel's career.

In 1913, Abel became interested in a potential method for the removal of diffusible substances from the circulating blood of living animals by dialysis. At the first inception of the work, he discussed his idea and plans with his staff at the luncheon table. The author can clearly recall this particular luncheon meeting. The professor used small cylinders of bread to illustrate how the apparatus was to be made and talked glibly about how this "artificial kidney" would be valuable to provide means for the removal of substances detrimental to the body in order to relieve the kidneys of their function and tide over a crisis. At this conception of the idea, he clearly saw the possibility of the use of his "artificial kidney" as a therapeutic measure for man.

The task was to pass the blood of an animal from an artery through a series of collodion tubes surrounded by saline solution back into a vein. Many technical difficulties had to be overcome but in November, 1913, the first successful experiment was performed on a rabbit. [See illustration between pages 16 and 17.] When the "old man" talked of the clinical application of the measure for the treatment of intoxications or to tide over when the kidneys were not functioning, his associates, including the author, considered him a bit of a visionary. In 1926, Haas of Giessen actually used an "artificial kidney" on three human patients. It was not, however, until 1946 that Kolff in Holland and Murray in Toronto were able to put the "artificial kidney" on what appears to be a workable basis. Great technical improvement has been made, but the idea and general principles are the same as those developed by Abel a third of a century before.

In connection with his studies on the "artificial kidney," Abel found from experiments on dogs that very large quantities of blood can be withdrawn repeatedly, if the red corpuscles of the blood are separated and reinjected in salt solution. The paper (1914) dealing with this 
work contains the following prophetic sentence: "In view of the fact that mammalian corpuscles retain their stability for three or four days when kept on ice, a supply of human corpuscles might possibly be kept in this manner in operating rooms for rapid injection in emergencies that would otherwise prove fatal." Here we have the fundamental idea of the "blood bank" which came into use only recently and which was of such great value in the treatment of wounded soldiers in World War II.

In the summer and fall of 1921, he became very much interested in biophysics, and wanted a department established in the Medical School. Actually, during the academic year 1921-22, biophysics is listed in the catalogue as a department of instruction. It was in charge of a lecturer in biophysics but was really under Abel in the Department of Pharmacology. Fortunately or unfortunately for the School at this time, the department only lasted a year, and Abel's attempts to get his colleagues to continue it proved unsuccessful. Today, biophysics is recognized as an important University department at Hopkins. It may be mentioned that at the time of his biophysical enthusiasm, Abel purchased from his limited funds an infrared spectroscope and had an assistant for two or three years working with it. Today, infrared spectroscopy is recognized as a valuable tool in organic chemistry.

Lastly, in a prophetic way, I can mention his intense interest in scientific journals and in the organization of national scientific societies. In view of the fact that he refused to allow himself to be sidetracked from his devotion to research to figure in the usual accompaniments of a successful scientist, medical meetings, committee meetings, and board meetings, it is somewhat difficult to explain his interest in scientific journals and scientific societies. The answer appears to be that he saw clearly the necessities of journals and societies in biochemistry and pharmacology and interested himself in them so that they might be properly launched.

Abel was first and foremost an investigator. His great enthusiasm and passionate devotion to research dominated his whole life. In one of his addresses, after discussing the training necessary for the medical investigator, wherein an extended chemical training is emphasized, he writes:

"But to what end is all this preparation for our young man? Is it solely that he may solve problems whose solution is of practical value to mankind? Is his mind to shape itself only to the insistent demands of utility? Even then our method of training will yield the largest profit.

"But it does vastly more than that. Thus trained, our young scholar 
will be able to see beyond the immediately practical problem, even though it be as great a thing as the discovery of the cause and cure of the plague that decimates a people. Greater even than the greatest discovery is it to keep open the way to future discoveries. This can only be done when the investigator freely dares, moved as by an inner propulsion, to attack problems not because they give promise of immediate value to the human race, but because they make an irresistible appeal by reason of an inner beauty.

"Some of the greatest investigators indeed have been fascinated by problems of immediate utility as well as by those that deal with abstract conceptions only. Helmholtz invented the ophthalmoscope and thus made modern ophthalmology possible, and at the same time did work of the highest order in theoretical physics and wrote on the nature of mathematical axioms and the principles of psychology. Lord Kelvin took out patents on great improvements in the compass and on oversea telegraphy and also made contributions to our knowledge of the ultimate constitution of the atom and the properties of the ether. From this point of view the investigator is a man whose inner life is free in the best sense of the word. In short, there should be in research work a cultural character, an artistic quality, elements that give to painting, music, and poetry their high place in the life of man." 


\section{John Jacob Abel: A Portrait}

PAUL D. LAMSON, M.D.

\section{$\mathbf{I}_{\mathrm{N}}$} N 1913 I was working at the University of London, the sole occupant of a new chemical laboratory attached to the Department of Pharmacology. I was swishing salt solution from one end of a dog's gut to the other, whistling to myself, and dancing a bit to keep warm, when I chanced to turn around and saw in the doorway with Professor Cushny a rather tall, thin man dressed in a morning coat, top hat, and spats, with an umbrella in one hand, a wire cage with two enormous toads in the other, and wearing on his face a composite expression of interest, surprise, and amusement which I shall never forget. It was in this way that I first met Dr. Abel, who was looking for someone who would deposit his precious Bufo agua in the Zoological Gardens until he demonstrated them at the International Physiological Congress which was to be held that year in London.

Several biographical sketches of Dr. Abel have already been written (1), the most complete of which is that by Dr. Carl Voegtlin, who has given us an exceptionally well-chosen outline of Abel's life beside an expert analysis of his work. Dr. Abel's personal correspondence from the time of his marriage was carefully saved by Mrs. Abel and is now in the hands of competent custodians, and it is expected that these letters from scientific men of all types in all parts of the world, covering a period from approximately 1885 to the time of his death in 1938, will be analyzed and published eventually in some form as an historical document, which should be of great value as giving us a picture not only of this truly great man but of the times in which he lived as well.

Although short, Dr. Voegtlin's biography is so complete that when I was asked to write this note for the Bulletin, I felt that there was nothing which I could add except my own impressions of Dr. Abel as I saw him during the years 1914 to 1925 . One should realize, however, that this was a very brief period in Abel's long life, that he was almost sixty when I first went to his laboratory, and that this was at a time when he had completed his active years of teaching and 
organization. In his early life he must have been a very different man from the one whom I saw. I have heard much from those who came before me, but it was always the same-amusing anecdotes mixed with the utmost admiration and in many cases an almost religious devotion for this man whom we all loved.

Dr. Abel's contributions to science were recognized the world over, as can be seen from the honors which he received. These are summarized as follows by Dr. Voegtlin:

He was awarded the Willard Gibbs, Conné and Kober medals and the medal of the Society of Apothecaries, London. Honorary degrees were bestowed upon him by the Universities of Michigan, Pittsburgh, Harvard, Yale, Lwow (Poland), Cambridge and Aberdeen. He was an honorary fellow or member of the following societies: New York Academy of Medicine, Association of American Physicians, Chemist's Club, Institute of Medicine of Chicago, Philadelphia College of Pharmacy, American Institute of Chemists, Royal Society of Edinburgh, Kaiserliche Deutsche Akademie der Naturforscher, Physiological Society of Great Britain, British Pharmacological Society, Society for Biology of Buenos Aires, Chinese Physiological Society, Société de chimie biologiques, Wiener Biologische Gesellschaft. He was a member of the National Academy of Sciences and in 1932 served as President of the American Association for the Advancement of Science. On the last day of his life he received notification of his election to a foreign membership of the Royal Society.

John Jacob Abel will be remembered as the first pharmacologist in this country and a member of that remarkable group of men who made up the first complete faculty of the Johns Hopkins School of Medicine, and for the part that he played in the founding of three of our most important medical publications, the Journal of Experimental Medicine, the Journal of Biological Chemistry, and The Journal of Pharmacology and Experimental Therapeutics. He was the pharmacological editor of the first of these, joint editor of the Journal of Biological Chemistry with Dr. Christian Herter, and the first editor of The Journal of Pharmacology and Experimental Therapeutics. He organized both the American Society of Biological Chemists and the American Society for Pharmacology and Experimental Therapeutics. His pioneer work on the isolation of epinephrine, the active principle of the medulla of the suprarenal gland, is known to everyone. His ideas of plasmapheresis and his so-called artificial kidney are equally well known, and his work on the phthaleins which culminated in kidney and liver function tests should be known by clinicians the world over, as they use these tests daily. The last work which received general recognition was his isolation of crystalline insulin. Besides 
this there were innumerable investigations which cannot be gone into here.

In order to obtain an insight into Dr. Abel's character it is necessary to consider his early training. As Dr. Voegtlin has done this so well, with his permission I am quoting him at length:

The life of this true scientist began on a farm near Cleveland, Ohio, where he was born on the 19th of May, 1857. Little is known about his parents save that his ancestors came from Germany.... At the age of 19 he began his college work at the University of Michigan. It was here that he took a course in physiological chemistry under Vaughan and physiology under Sewall. His college education was interrupted for three years during which time he was Principal of the high school and later Superintendent of Public Schools at La Porte, Indiana. He received his $\mathrm{Ph}$. B. degree from the University of Michigan in 1883. After graduation he married Miss Mary Hinman, a teacher in his school at La Porte...

The first academic year after graduation was spent in the Department of Biology of the Johns Hopkins University under Newell Martin, the able pupil of Michael Foster....

At this time, in 1884 , at the age of 27 , he made the important decision to study medicine in Europe. Throughout his seven years of European study he showed a remarkable ability to select as his teachers many of the distinguished men of this period. From 1884 to 1886 he was in Leipzig, studying physiology under Ludwig and von Frey, histology under His, pharmacology under Boehm, pathology under Strümpell, and inorganic and organic chemistry under Wislicenus. At the same time he completed his doctor's dissertation in Ludwig's laboratory. The winter semester of 1886-87 was spent in Strassburg under Kussmaul in internal medicine, under v. Recklinghausen in pathology and infectious diseases. The following summer semester he studied at Heidelberg with Erb in medicine and Czerny in surgery. During the summer vacation he attended clinics at Würzburg; 1887-88 brought Abel back to Strassburg where he took courses under Kussmaul, Naunyn, Hoppe-Seyler and Schmiedeberg. It was Schmiedeberg who aroused Abel's first interest in pharmacological research, particularly in its chemical aspects. In 1888 he received his M.D. degree from Strassburg. On October 30 th of the same year he suffered the loss of his infant daughter, a severe blow. It is not unlikely that this loss determined him to leave Strassburg, where he had found so much inspiration and had made many friends, in order to pursue a year of postgraduate clinical work in Vienna with Nothnagel and others. But his yearning for laboratory research found Abel in 1889 to 1890 working in the laboratory of the outstanding biochemist v. Nencki in Berne, Switzerland. It was here that Abel obtained his first training in chemical research. In later years he often enthusiastically referred to this stimulating experience. There can be little doubt that at that time Abel had a clear vision of what a tremendous part chemistry was to play in the future of scientific medicine. Therefore, he resolutely determined to be prepared, irrespective of the expense involved which he could hardly afford. In Berne he completed a research on the "molecular weight of cholic acid, cholesterol and hydrobilirubin." Using Raoult's method he called attention to the limitations of this method for the purpose in view. Another paper dealt with the chemical composition of the melanins from hair and melanotic 
tumors, showing that these pigments did not contain iroll in significant amounts. In Berne he formed a life long friendship with Cushny, who at that time was working in the laboratory of the Physiologist Kronecker.

After this year with v. Nencki, it was Abel's intention to return home where he expected "to carry on medical practice and to do some research work, if possible, in internal medicine in connection with one of our American medical schools." This decision was partly due to the advice given in a letter by H. C. Wood, who, though recognizing Abel's "extraordinary training," told him he must first be known in America as a lecturer and independent investigator in order to have a chance to get a professorship of from $\$ 1,500$ to $\$ 3,000$ a year. However, the outlook for a clinical career would be more "promising." Having used up all his funds Abel decided reluctantly to enter clinical work. Then in the late summer while still in Berne, Abel received a cable from Vaughan which was the turning point in his life. On Schmiedeberg's recommendation Vaughan offered him the Chair of Materia Medica and Therapeutics in the University of Michigan, with the understanding that he was to establish a modern department of pharmacology; materia medica and therapeutics being retained in name only. Here was the chance Abel had looked for to enter a career in experimental research and with $\mathrm{v}$. Nencki's advice he accepted the offer to return to his Alma Mater. But before returning home he induced Vaughan to let him have a last fling at biochemical research with the able biochemist Drechsel in Ludwig's laboratory. Drechsel at that time was doing important work on the chemistry of proteins and on protein metabolism. Drechsel and Abel thus began a joint research on the occurrence of carbamic acid in alkaline horse urine. This association led to a close friendship which lasted until Drechsel's death in I897.

On his homeward journey Abel stopped at Berlin to obtain first-hand information on Koch's tuberculin treatment, which had attracted international attention. This was the subject of his first lecture at Michigan in January, 1891. In a Ietter to C. W. Edmunds he writes: "Here at Ann Arbor I was given the opportunity of starting the first professorship of pharmacology in the United States, whose holder should devote himself entirely to giving students the best possible instruction by means of lectures, demonstrations and quizzes, in the manner in which my European teachers (Schmiedeberg and Boehm) had long carried on their work. All my energy that was not given to this kind of instruction to students was devoted to research work and to arousing the enthusiasm of others for it.... There was no laboratory of any kind at my disposal. There was not a scrap of apparatus, not even a test tube, a flask or a beaker." But soon he had organized his small laboratory and with a senior student, Muirhead, he immediately gave demonstrations on animals and carried out a research on the occurrence of carbamic acid in human and dog urine following the administration of large amounts of lime water....

While Abel was active in Michigan the Johns Hopkins University under President Gilman began the organization of its medical school. Welch, Osler, Halsted, and Kelly had already been appointed, and equally outstanding men were needed to fill the chairs of the preclinical subjects. In January of 1893 Abel received a letter from Osler inquiring whether he would be a candidate for the chair of Pharmacology. He replied that he was strongly attracted by the prospective intellectual contacts with Osler, Martin, Welch and Remsen. His main concern, 
however, was the provision for adequate laboratory facilities. His appointment to the Professorship of Pharmacology went into effect for the academic year starting in the autumn of 1893 and with it Abel reluctantly also assumed the responsibility of giving the course in physiological chemistry. Before assuming his duties he obtained a few months of leave to complete some research with Drechsel and to consult his old teachers in Europe.

What was it that caused Abel to make such effort and sacrifices for this very advanced education, and how was it that he showed such extraordinarily good judgment in choosing the men with whom he worked and in training himself along the lines which he did? That he was not content with a safe and respectable position as Superintendent of Public Schools in a small city shows that at an early age he was in some way inspired to go further. Was it his association with Vaughan or Sewall at the University of Michigan which led him to go to the Johns Hopkins University under Newell Martin, and was it Martin who suggested that he take up medicine? Regardless of who may have given him such ideas or advice, it is obvious that Abel was no ordinary student but one filled with an intense desire for the best. His ability at the time of his studying medicine, to choose the best men in the world, was no mere accident, but this trait continued throughout his long life, and when his life is written in full, it will be found that the greatest men of these times were among his friends and correspondents.

In these days it is difficult for us to comprehend the difference which existed in 1885 between medical science in Europe and in this country. Here, biological chemistry was not then sufficiently differentiated from physiology to warrant the formation of a separate group of biochemists, and pharmacology did not exist. It is safe to say that chemistry was hardly known to the clinicians, who at about that time were beginning to take up the new field of pathology. As late as 1911 Dr. Reginald Heber Fitz, then Professor of Theory and Practice at the Harvard Medical School, who was one of the outstanding men in clinical medicine in those days, advised me strongly not to take up chemistry in relation to medicine. He said he realized that someday it was coming into medicine but that he had watched it all his life and was sure that it never would amount to much in my day. Yet twentyfive years before this, Dr. Abel with his medical training and medical degree realized the importance of chemistry and specialized in it. He was probably one of the very rare men in this country who then had anything like this training, and it was this knowledge, which others did not have and could only partially appreciate, that had a great deal to do with the foresight attributed to him. He had worked in Europe 
with experienced biological chemists and pharmacologists and had read their journals, all of which impressed upon him the need of similar organizations and publications in this country. His knowledge of chemistry allowed him to go more deeply into fundamentals than was possible for many others. Then, too, the whole scientific life of the remarkable group of German medical men who lived at that time made a deep impression on Abel. Their almost monastic devotion to medicine, their ability, modesty, the care and exactness with which they did their work in infinite detail, and their desire to find out the truth of matters gave him very high standards for his own development.

To Professor Abel this group always remained different and above all others. He would speak in a hushed voice of the great Naunyn or the great Nencki, and in a discussion the last word had always to be found in a German reference book or article. This was a great group, and those must have been wonderful times when, as Abel put it, he "walked the wards with v. Recklinghausen." But all of these men and these days have gone, and one wonders whether a professor will ever be as much of a professor as he used to be then, whether the professorial, broad-brimmed, black felt hat will ever again attract the same awe and respect that it did, and whether it will be possible as it then was to determine the departmental rank of a group by their relative positions as they walked down the street.

Professor Abel's work was largely of a biochemical nature, for example, that on the chemical composition of the melanins from hair, the occurrence of carbamic acid in alkaline horse urine as well as in human and dog urine, the chemistry of the pigment of the negro's skin and hair, the isolation of ethyl sulfide from the dog's urine, and an attempt to isolate the active principle of the thyroid, his isolation of the active principle of the thyroid, his isolation of the active prin ciple of the adrenal medulla, his work with Ford on the poison of Amanita phalloides, a study of the active principles of the secretion from the parotid gland of the tropical toad Bufo agua, his classical experiment demonstrating with his "vividiffusion" apparatus the presence of amino acids in the blood. Then there was his work with Pincoffs and Rouiller on the presence of albumoses in the tissues and in the blood as well as in the gastrointestinal mucosa, his work with Geiling on Witte's peptone, as well as that on the active principles of the pituitary gland, his chemical studies of and isolation of crystalline insulin. These indicate Professor Abel's real interests. His work on the phthaleins and their use in kidney and liver function 
tests, his entrance for a short time into the field of chemotherapy with his studies of the antimony thioglycollates, his plasmapheresis and his vividiffusion ideas were more or less side interests which kept him from his main line of work for a short time only.

The fact that Dr. Abel had to take over the teaching and laboratory work in physiological chemistry when he first went to Johns Hopkins probably had little to do with this biochemical point of view. His interest was definitely chemical before he went there, and although he was always attracted to a great variety of problems having to do with medicine in general, his primary interest seemed to be in the fundamentals of the living organism rather than in the secondary changes brought about by disease or intoxications produced by drugs. It will be noted that, except in very few instances, Dr. Abel paid little attention to studying the action on the organism of the substances with which he worked, that is, their so-called pharmacological action. True it is that he used the reactions of the organism to separate his various fractions and eventually his pure principles from complex mixtures, but it was his aim to discover what these principles were chemically rather than to study the complex reactions of the organism after their injection.

On returning to this country in 1914 after two years in Europe, I found that my hearing would not allow me to go on with the clinical work which I was then doing at the Peter Bent Brigham Hospital in Boston, and while wondering what could be done about it I suddenly thought of how Professor Abel looked when I had seen him that morning with Cushny in London. I immediately wrote to Dr. Abel and asked if I might come to work in his laboratory. He replied at once in the most friendly manner urging me to come there, and I left for Baltimore wondering what I would find to do. After the white marble walls of the Harvard Medical School and the new Brigham Hospital, the Johns Hopkins Medical School building of that day was not an impressive sight. My spirits went down as I climbed the three long flights of stairs to the pharmacological laboratory where I found Professor Abel in his small corner room, a test tube in one hand and a capillary pipette in the other, in the process of adding a minute drop of some extract to a solution. He immediately put these down and greeted me with the utmost cordiality. In one corner of the laboratory was an old, roll-top desk piled high with papers of all kinds; and every available and unavailable space on the desk, a revolving bookcase, and a rather large table was heaped with books and current periodicals. Within three feet of his desk was a standard 
chemical bench, behind which was an ordinary canvas army cot. There was a hood in one corner and a sink next to the door. There was no room for anything else. There was nothing new in the room; everything in it looked as though it had been used continuously for many years. I later found that there was one exception to this-a new, large Webster's Dictionary which had escaped my attention, as it was kept rolled up in a green cloth and tied with a string. In spite of this, however, it was very often used.

After a word or two of greeting I started to tell Dr. Abel about my forced change of plans, but he interrupted me almost at once, saying, "That is too bad, but let us put that off until we have an evening at our house together. If you have no problem on hand at the present minute, let us start on something which has become of the greatest importance on account of the war." He then suggested that we attempt to treat pig's blood so that it could be used in man to replace human blood without causing hemolysis and reactions of one sort and another. This sounded a bit wild to me, but I did not dare to say so. He gave me a white coat of his own, hung mine on a hook on his door, sent the laboratory boy to the nearby slaughter house for pig's blood, and within fifteen minutes after I came into his room I was actually at work and on a problem which kept me busy for over ten years although it was not two days before I gave up the pig's blood idea forever. How many men would have been able to diagnose instantly the state of confusion brought about by such a change in one's life and without a word have started one off on a course which effected a cure almost instantaneously?

At just the time I went there, Baltimore was starting to grow up and to lose much of its old charm, which, however, has been replaced by much of beauty. The automobile was just coming in, and a few people were moving out of town, but many of the best families still lived in the city and sat on their doorsteps after dinner on warm evenings; and on the way home it was the custom for one to drop into the Maryland, Baltimore, or University Clubs, where one was sure to find friends. The University had not moved out to Homewood, and I lived and dined with a very pleasant group at the Johns Hopkins Club on the corner of Monument and Howard Streets. Each morning we would walk across town to the School. As we began our pilgrimage we would pass houses with beautiful doorways, the brass knockers and nameplates of which were being polished by those fine old colored men of the old school, and before we had passed the Washington monument, we were sure to have been greeted with a 
"good morning, Major, Colonel, General, or Admiral," which, in spite of slight exaggeration, gave one a sense of importance with which to begin the day's work. Going over the hill and past the railroad tracks one saw those marvelous, great horses, eight or ten at a time, which pulled freight cars through the streets, but after this the glamour disappeared, as one had to watch his step to avoid the sewage drains which ran uncovered across the sidewalks in the famous Baltimore sewage system, and there was nothing left but a long climb up to the hospital, which tapered off from a very imposing front, to Dr. Welch's laboratory across the street from Hanselmann's saloon, to which was attributed the entire success of the early Johns Hopkins group.

Professor Abel was at that time very comfortably settled in an oldfashioned house with high-ceilinged rooms and a cupola, just off Charles Street very near where St. Paul Street comes into it. Guilford itself had not been developed at that time although the streets were laid and a few houses started. The Professor kept a cow, for which there was plenty of room, as his land ran down across the railroad track and up a hill on the other side and must have covered between ten and twenty acres. I had been in Baltimore for a day or so only when I was asked to dine at Dr. Abel's house and went there part way by trolley and the rest by bus and was most cordially greeted by Mrs. Abel and the Professor. The house was to my mind an almost ideal place for a professor; everything about it was livable, inside and out. There was a large study on one side of the front hall, a living room on the other, behind which was the dining room. In the study there was an old-fashioned, marble fireplace with a coal grate and a fire always burning. The rvalls were very high and completely lined with bookshelves. The Professor's old-fashioned armchair was pulled up casually before the fire, and in front of it was a footstool high enough to make it possible to put one's feet on it and stretch out comfortably in the chair, which the Professor used to do on less formal occasions. Pulled up beside the chair was a table piled with books, periodicals, and papers. The furnishings of his house, like his laboratory, were ample but simple and looked as though they had been chosen for use and used. I went to many evening and Sunday dinners at this house, and those whom I met there were almost always workers in the laboratory or out-of-town or foreign visitors, of whom there were many. There was always so much of immediate interest going on in Dr. Abel's mind in connection with his own work or that of his guests that conversation usually centered about such matters. This always came about most naturally and was in no way forced. 


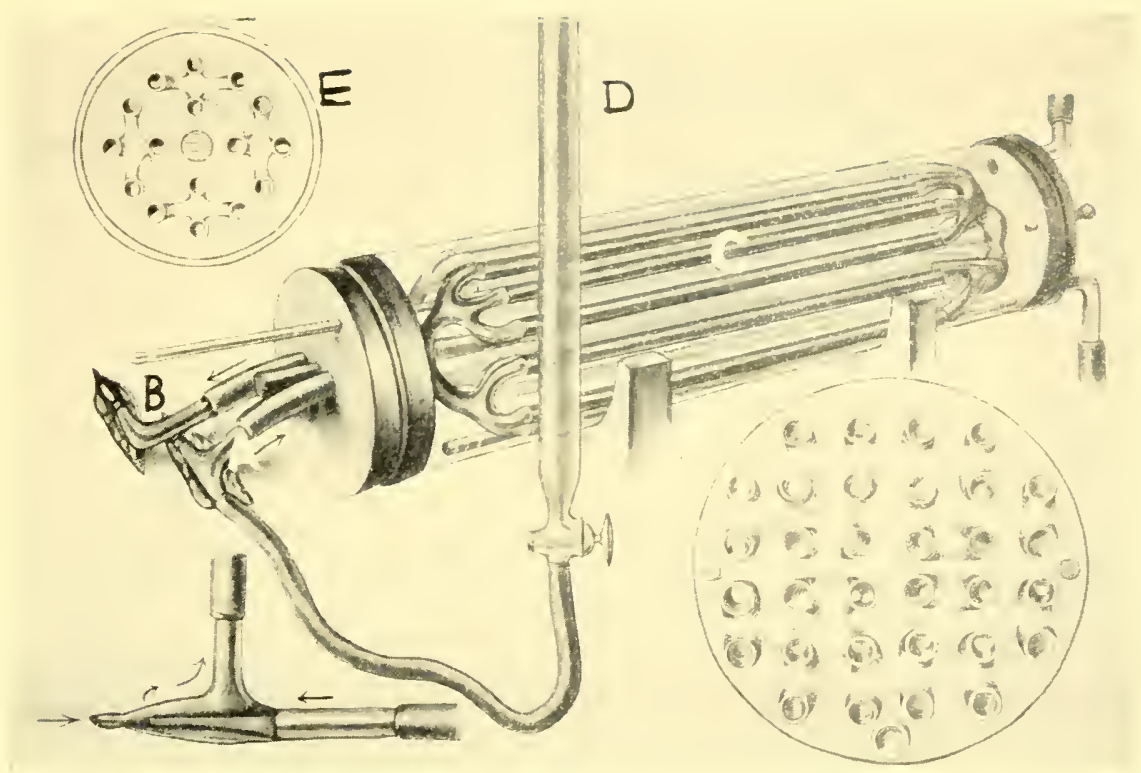

Figuri 1. "Artificial Kiclney" was enrisioned by Dr. Abel years before one was fmally developed which would work on human patients. The view above, reproduced from an old drawing, shows the artificial kidney used by Dr. Abel on animals in 1913. A cannula (tube) was inserted in the animal's artery (A) to lead blood into the device's apparatus (C), a series of collodion tubes through which the blood flowed and from which substances in the blood were diffused into a Huid introduced from ontside. A cross-section of these tubes is shown in the (ircle at upper left (E). Anticoagulant was introduced through the burette in center of drawing (D). Blood was returned to vein of animal through upper cannula at left (B). 


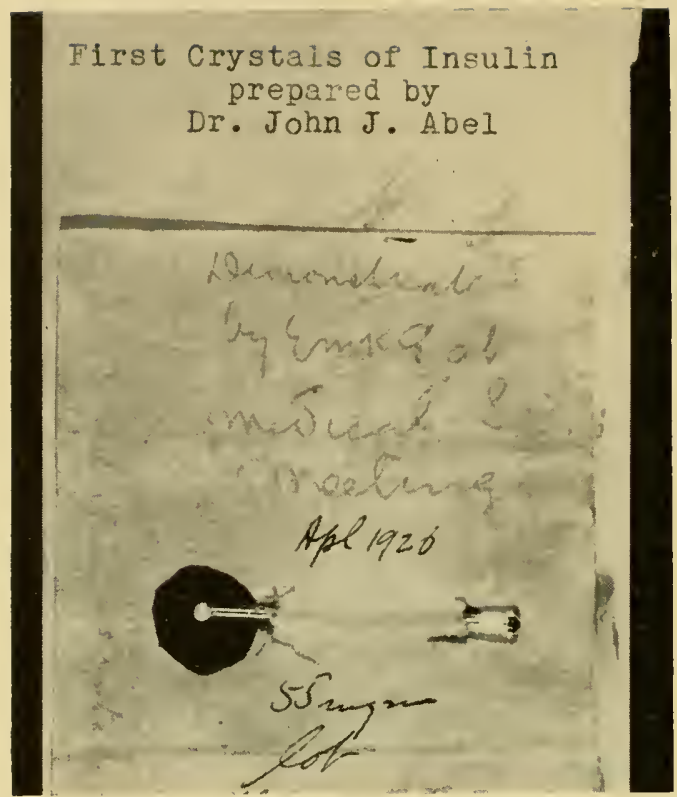

Figure 2. Dr. Abel was the first to obtain insulin in chemically pure crystalline form. He isolated the hormone when he was sixty-nine years old. For months after he first did it, he was umable to repeat the performance, and many chemists were skeptical of his achievement. Ultimately he found the answer and crystalline insulin is now commercially prepared.

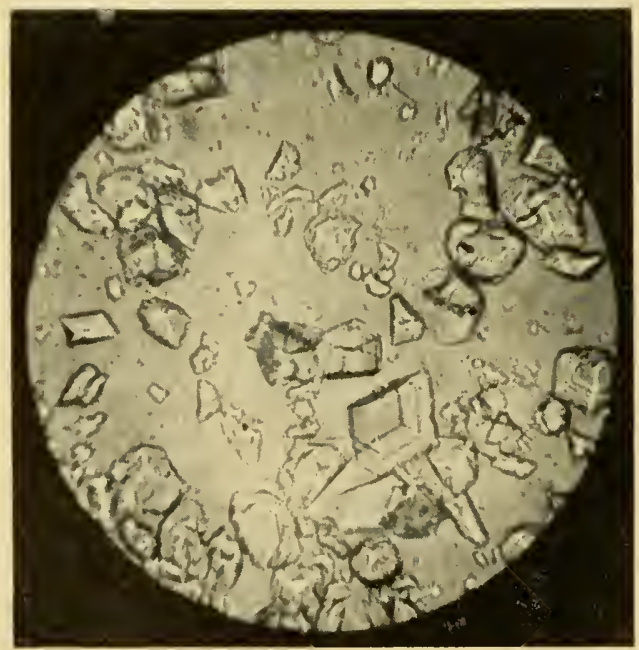

Figure 3. How Abel's first insulin crystals (still kept at Johns Hopkins) appeared under the microscope. 
Then, of course, there was the war, at that time in its early stages, before the United States took part in it. Professor Abel was very pro-German, which may have been on account of his ancestry but much more likely on account of what he knew of Germany as he had seen it. This made it utterly impossible for him to believe that the Germans were what they were made out to be at that time, and it was equally hard for me to believe it then. The war liad a great effect on the Professor and upset his life tremendously. At first it was very stimulating to him, as the Germans made new advances almost every day, and this was reflected in the way he walked as well as talked. Both Dr. and Mrs. Abel were extremely kind to me and treated me almost as a son. In fact, they asked me after a time to live at their house with them, but I did not accept this invitation for two reasons: one was that although I was fond of medicine, I did not want to give up everything in life to the whims of this man as all who came very close to him had to do on account of his complete absorption in what he was doing to the consequent oversight of everything else; the other was that my love for the Germans became less and less, and, finally, in order that there could be no misunderstanding on this point in Professor Abel's mind, I wrote him a letter telling him that I thought he should know of my having lost all faith in the Germans and that I was going to take the part of the other side. Although I did this as kindly as I could, I do not think that the Professor ever quite got over it.

For a time, after the war was over, he was much depressed and very bitter, but with his usual and extraordinary ability to take reverses he shook off this depression and went to work with renewed vigor. Unfortunately, at just this time the laboratory was overwhelmed by a group of South Africans who were extraordinarily anti-British in their sentiments. For several years the lunch-table conversation degenerated into anti-British tales raked up from all possible quarters by this South African group. I, who was no historian, could stand this only so long and then would blow up, to be put in my place again on account of lack of evidence on my side, and since there was no one there to back me, I became less popular daily. But this group and this period passed, and in his later years I heard nothing more of the war from Professor Abel. I am sure that his anti-English remarks were purely an attempt to justify what the Germans had done, because he told me many times that when he retired, his one desire was to go to England and spend his last days with "that wonderful group of English physiologists." 
I had been told that it would be a waste of time to go to Baltimore to work with Abel, because he was always too busy with his own work and I would see nothing of him. When I arrived, he had just been asked to write the first Mellon lecture (2) and devoted the better part of a year to the preparation of this. Anyone wishing to get an idea of the thoroughness with which he did things, and of the breadth of view which he had, would do well to read this as well as his other addresses. This would also give one an idea of Dr. Abel's feeling that one should give all that one had to whatever was being done. During the first year that I was in his laboratory he carried out almost no experimental work and would drop in to talk for hours at a time. We would often leave the laboratory early and drive about the country, ending up at his house for tea or supper; but after this first year things were very different, and except when he came out of the seclusion of his corner laboratory for lunch or to carry out an animal experiment in the large laboratory, one saw very little of him.

I shall never forget the day Dr. Abel decided he should move. A real estate company made plans to develop what is now Guilford. This involved the house and land where Dr. Abel lived. They tried to induce him to build another house, but he was afraid of 'being crowded', as he put it, and decided to go elserwhere. I had an old car at that time and spent many afternoons driving Dr. and Mrs. Abel all over the country looking for another house. One afternoon as the day was getting on and with a violent thunderstorm coming up, we drove out some ten miles from the middle of the city and up a hill where there was an enormous unoccupied house very similar to the one in which he used to live on Charles Street. This was off the Windsor Mill Road and had fine grounds with wonderful, great trees, a driveway lined with hemlocks, the same type of cupola on the house, and goodness knows how many rooms. The house was by no means in the best state of repair, and neither were the grounds. The Professor jumped out of the car and rushed into the house, leaving Mrs. Abel and me behind in the rain. Mrs. Abel got slowly out of the car, stood looking at the house in a horrified manner, and, turning to me, said in her quiet way, "My goodness, Dr. Lamson, did you ever see anything so awful?" A few minutes later Dr. Abel came dashing out of the door shouting, "Mary, this is just exactly what we want." Mrs. Abel then went in, looked the house over, and said, "Yes, I think this will do very well indeed." This was typical of Mrs. Abel. I have never seen such devotion in anyone as she had for the Professor. It made no difference what his plans might be, 
they were accepted at once by Mrs. Abel, who not only willingly but with genuine enthusiasm cooperated with him. If it were a minor matter such as unexpectedly bringing people to dinner, giving up engagements, taking a train for other parts, or changing the entire way of living, it made no difference whatever, Mrs. Abel agreed at once, and never did any of us hear her complain. Until Mrs. Abel died, she lived on this hill. At first she had a colored boy to help her, but he was a character and more trouble than help, and she soon gave him up.

Among the letters which came to me at the time of Dr. Abel's death was one from Professor Walther Straub, who told of his coming to this country to lecture and being met at the station by Professor Abel. It was some minutes after the train came in before Professor Straub saw him hurrying down the platform; Dr. Abel greeted him in an excited manner, saying. "I am sorry to be late, but Columbus only just arrived." Straub said that he was much shocked and thought that the Professor was losing his mind, and it was only when they reached the car that he found that Columbus was Dr. Abel's colored boy.

In these days of new schools and perfect equipment it might be interesting to consider the surroundings in which Professor Abel carried ont the work which has made him famous the world over. As I have said before, the Medical School was by no means an impressive sight. Each story was very high, and Dr. Abel's laboratory was on the third floor. There was no elevator except a small freight affair which had to be pulled up by hand. There was a hallway around the stair-well from which the various laboratories radiated. I have no doubt but that everything was done very systematically when Dr. Abel was younger, but when I reached there, it was a case of every man for himself, and there certainly was no system about anything. There was only one kymograph in the laboratory which worked, and that was a long paper electrical affair, and to do a blood pressure experiment involved as much as a major surgical operation. Since I was the youngest and newest arrival, I was not allowed to take part in such an important event as doing a blood pressure experiment on a dog, but I was allowed to watch. Dr. Rowntree had just left, and Dr. Marshall, who at that time did not even know where the kidney was, and a physical chemist from Europe, who was not quite sure whether a dog had a kidney, supervised the operation, which was done by Charlie Kamphaus.

Outside Professor Abel's laboratory Charlie was the Department 
of Pharmacology. If you wanted anything, you asked Charlie for it, and if he happened to be out, you simply did nothing until he returned. I asked him once how it was that none of the large stock bottles had labels on them, and he said in the most hurt manner imaginable, "Why, Dr. Lamson, if we had labels on them, everyone would know what was in them." At another time I asked him to return something which we had borrowed from another department, and he said, "Don't do that now. If you wait a little longer, they won't remember that you have it." Charlie was a German, short, well-fed, but not fat, then. He was the most good-natured, willing, hard-working soul I have ever seen. He existed for one thing only, and that was to serve Professor Abel. Sundays, week days, or holidays the Professor would merely say, "Charlie, keep your eye on this dog, you must look at him every two hours," and Charlie would be there day and night. If the Professor suddenly wanted a dog and there were no dogs in the animal house, it never occurred to Charlie that this could be anyone's fault but his own, and with tears in his eyes he would dash about from one department to another looking for a dog. Charlie liked to work and confided to me once that the height of his ambition was to be a waiter in a beer garden where there would be twice as many people as one could possibly serve, and just as you had supplied one table with beer they would shout for you to fill up the glasses again, and you would know that you could not possibly do it.

Charlie was assisted in these blood pressure operations by Charlie, Charlie Drain, a devout Irish Catholic with the good and bad qualities of a bulldog, very fond of liquor, who died of delirium tremens during the prohibition period. He worshipped the Professor but was not as sophisticated as Charlie Kamphaus. His one desire was to find someone who would say something against Dr. Abel so that he could, as he put it, "knock his block off." Together the two Charlies would put the dog under ether and hitch up the blood pressure apparatus and kymograph. Things would usually have worked fairly well had it not been for the fact that the recording was done by means of glass pens blown by everyone who had ever been in the laboratory. The experiment would start, and then the pen would weep and the ink run down the paper, whereupon both Charlies would discuss the advisability of putting on another pen, and this as likely as not would refuse to write. In the excitement one or the other Charlie would blow through it. After a very short time both of them were red ink from ear to ear. If the experiment were a long one and artificial respiration were needed, another assistant was called in, Mrs. Thomas, the scrub- 
woman. Mrs. Thomas was getting on in years, was very fat and very polite, and also a devout Catholic. She would sit on a stool at the dog's head and pump away on a pair of hand bellows, but she had a habit of dozing off very frequently and had to be waked up, usually by Charlie Drain, with a polite nudge and the remark, "A little more air, Mrs. Thomas, please." At one time Mrs. Thomas' husband had to be dug up and moved, and for years after this during lulls in an experiment she would describe in great detail just how he looked and the various colors of his face. This always ended in tears, and we had to distract her with a call for more air. After all was well under way, and while the chemists were giving general directions, entirely unheeded by the operating staff, Professor Abel would be ceremoniously called by Charlie Kamphaus, and he would appear with his little glass evaporating dish, his capillary pipette, and his notebook. A hush would come over this scene of blood, red ink, and artificial respiration, and the Professor, entirely oblivious of everything, would fill a syringe, and someone would make the injection for him.

In the early days when I first went there, Professor Abel wore a white laboratory coat. Later, he added to this a white apron which he had become interested in, because Dr. Binger wore these. As time went on and as the laboratory was none too well heated, Professor Abel added an ordinary sack coat over the apron, and some years later discovered a very long, heavy, red rubber apron, which he then wore underneath the white one. At about this time Dr. Abel had his portrait painted in a gown with which there was a black velvet hat which pleased him a great deal. He often spoke to me about what a nice thing this hat was and how he thought it a splendid custom to wear such a hat. One day a member of the surgical staff cane into the laboratory for luncheon wearing a white operating cap, and I noticed that Dr. Abel was particularly abstracted that day and kept looking at our visitor with an interest all out of proportion to what the surgeon's conversation seemed to merit. After lunch the Professor took me aside and asked if I could manage to get him one of those little white hats. I did, and he wore it to the end of his days.

On the street and around his house Professor Abel was always very spry and walked with great alertness and rapidity, but for several years I had been semiconscious of the fact that he went about the laboratory in a decrepit manner. He would come out of his room and shuffle across the laboratory with very short steps, almost on his toes, and always holding his evaporating dish in one hand and his pipette or his notebook in the other. One day I happened to notice that he

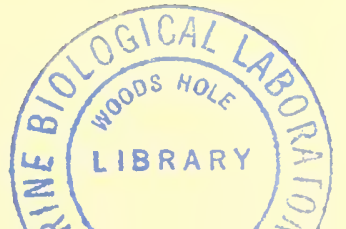


held up his apron with one hand, as one would a skirt, and becoming interested in this phenomenon, I saw that the band around his neck was so long that the rubber apron nearly touched the floor, and the string, which should have gone around his waist, tied his knees together so that it was impossible for him to take a long step. I asked if I could not shorten the neck band for him and explained what seemed to me to be the advantage of doing this, but lre only looked at it in a dreamy sort of way and said that it was all right as it was, and it stayed that way as long as I was there.

When one of these blood pressure experiments was over, the record was rolled out on the floor, often running the entire length of the large laboratory and even out into the hall. Everyone would very seriously gather about it and walk up and down the record looking for results. No one ever seemed to be the least bit aware that this was not the accepted method of carrying out such experiments.

The laboratory was well equipped for special chemical work, but except for this one kymograph there was almost nothing in the way of apparatus. There was one microscope in the department in use, and that belonged to me. After some ten years when I needed a microscope badly and everyone was using mine, I asked the Professor if the one which he had in his laboratory could not be turned to general use. I had seen this in action only once. It was kept in a wooden box done up in a brown cloth, tied with a stout cord, and the whole thing wrapped in an old, white laboratory coat and locked in a case in Professor Abel's room. He looked very much taken aback at such a request on my part and asked what was the matter with the one we were using. I told him that there was nothing the matter with it, but that it was mine and that we needed another. He said, "But, Lamson, the microscope that I have is a good one." When I answered that mine was also, ten years ago before everyone used it, he looked at me hard without saying anything, and then a quiet smile came over his face, and he turned and walked away. In a few minutes he came back to my room with the precious machine of his own and left it without a word.

We had no shop, and when I tried to make a perfusion apparatus and needed to make a thermostat, the only tools which could be found were a hammer with a split handle, a screwdriver, and a keyhole saw with half the blade broken off. With this outfit I managed to put together a thermostat made out of a soap box, which worked surprisingly well until one day when I was out of the room I heard a great commotion and someone shouting, "Fire!" I came in just in 
time to see Professor Abel emptying the last of the contents of a large fire extinguisher into the middle of my precious apparatus, of which there was nothing left.

At night the heat went off in the laboratory, and it became extremely cold. Someone broke into the Medical School at one time, after which rather unusual precautions were taken to keep a further break from occurring. These consisted in locking up the gate to the high iron fence which surrounded the Medical School, and no keys were given to any members of the faculty regardless of our pleas. When one came over in the evenings to work, on an icy, snowy night, and had to climb this high, iron fence with its arrow-shaped spikes, then feel one's way into the basement in utter darkness, locate the main switch of the building, turn that on, and then climb three flights of stairs in the dark on account of an economical lighting system which had been developed, it often took some time to quiet one's resentment against the powers that had developed such plans, especially those who did not have to climb the fence.

In spite of all this, the laboratory was one of the finest to work in that I have ever seen. Everything was informal, and Professor Abel had that very rare faculty of being willing to see a change made in anything at any time. Once while I was there, a plan was developed to move the Department of Pharmacology to the new Hunterian Building, which to my mind would have ruined the spirit of the Medical School, as it would have separated biochemistry, physiology, and pharmacology, but when this was suggested to Dr. Abel, he was perfectly willing to make the change if others thought it best for the School, in spite of the fact that it would upset his work for a considerable length of time.

If the Professor was a trifle thoughtless about the comforts of his assistants, he was equally thoughtless about his own. For instance, he had no telephone in his room, and for a long time, in order to use one, he had to come out into the hallway and squeeze into a horribly small closet which was a sort of dump for dirty laboratory coats, the janitors' shoes, etc. For a great many years he had no secretary, and it took a lot of persuading in order to get him to take on even a halftime one. The Professor immediately installed a telephone on her desk, but he himself still had to go through Dr. Marshall's laboratory, out into the hall, and carry on his telephone conversation in this stuffy closet. As it became annoying for the secretary to go constantly to the Professor's room and call him to the telephone, she installed a buzzer on his desk so that it was only necessary for her to press a but- 
ton and the Professor would scurry out to the telephone. It was several years before we could convince him that he deserved to have an extension telephone on his desk, which he finally did with great reluctance.

To me it seemed that Professor Abel lived in the clouds rather than in this world. However, he was an extremely practical person when his attention was focused on something, as can be seen from his organization of scientific societies, journals, his laboratories, and courses for both biological chemistry and pharmacology. It was he who advised Mr. Passano of the Waverly Press to specialize in the publication of scientific periodicals, a thing which had not been done in this country before and which was followed with very great success, on account of which Mr. Passano has written a very fine tribute to Professor Abel. But everything having to do with the laboratory, his work, and science had a supernatural interest for him. When he would come in to see an experiment, Professor Abel would talk in a hushed voice. He would speak with the greatest reverence of scientific publications and men, as well as their work. He gave to science a certain halo, which at times seemed out of place in our humdrum life of America but which corresponded to that aura which enveloped a German professor in Europe. This was very greatly appreciated by some who worked with him, and I am sure that it was entirely sincere and natural to Professor Abel but not in others who attempted to copy him.

That Dr. Abel had courage is well known to anyone who had anything to do with him. After months of work when he fully expected that a final experiment would prove what he had been seeking for all this time and it proved the exact opposite, he would draw himself up, shake his rather frail shoulders, and say, "Oh, well, there are many fish in the sea," and immediately begin on his work again. In the course of his early work on epinephrine an explosion occurred which filled his eye with glass and must have been an extraordinarily painful affair, but those who were with him at the time told of his great courage then and during the removal of his eye under local anesthesia. He almost never spoke of this in any way, but one time did tell me that it was quite interesting when they cut through his optic nerve. In minor matters, however, I think he more or less enjoyed having something happen which made him exert himself against circumstances. He used to tell the most extraordinary story of how a nurse accidentally poisoned him with atropine in the hospital. After he underwent a rather serious operation at one time and, again, when he 
broke his leg, there was no reason for, and much against, his hurrying back to his laboratory, but I think he more or less enjoyed seeing whether he could do it or not.

Dr. Abel belonged to that generation which has just passed, in which men still liked to think that they might know about everything although they were perfectly well aware of the fact that they could not. I believe, however, that this irritated Professor Abel considerably. He seemed a trifle jealous of Dr. Welch, who had such an unbelievable memory and who seemed to have had some firsthand experience with almost everything that had happened in medicine. When a new edition of the Encyclopedia Britannica came out, he confided to me that he had heard that Dr. Welch was reading it from cover to cover, but I know that he read a great deal of it himself with a great deal of interest, for he used to point out the mistakes in it and tell me how much better the German encyclopedias were. He used to like to dabble with Greek and Latin and has sent me postcards written in Greek, which I hope were more intelligible to him than to me. I dropped in on him one time at Randolph, New Hampshire, where he used to spend the summers, and found him studying Latin grammar. He explained to me how he had tramped over the whole Presidential range with his sons, and another time he told me how he had spent several summers cruising from Baltimore up to the coast of Maine and back. This was no mean undertaking for a man unaccustomed to the sea. He apparently went at it with great thoroughness, however, hired a skipper and a good-sized boat, and took his family over these many miles of ocean without a mishap. I found, however, that Mrs. Abel was none too pleased with some of these trips. When a storm came up, the Professor felt that the deck was no place for a woman, and he not only put her below but shut all the hatches in a supposedly seamanship manner, and Mrs. Abel admitted that these were not the best days she had ever enjoyed.

The Professor also had a fondness for mathematics and physics, but I never realized what a sacred field this was until one day, while we were having luncheon, Rouiller was extracting a vacuum desiccator by means of a very noisy water pump, and Professor Abel got into an argument with one of the staff members as to whether molecules could or could not pass through a hole in the desiccator in a certain way. I do not remember what the argument was about but only that I heard the Professor say that molecules could not pass through this hole, and I made the unfortunate statement that I thought I could make them pass through so fast that they would 
whistle. My remark was an entirely casual one, based on no knowledge of the matter whatever, but it upset the Professor as much as if Einstein had said it. He immediately pulled out a pencil and paper and started to prove to me how I must be wrong. I then became enough interested to believe that he could not be right, and we discussed this matter all of one afternoon without leaving the lunch table. I kept trying to get out of this by saying that it made no difference what the molecules did, but the Professor kept saying, "But this is a very serious matter with me. You know I taught physics once." At about the time we should have left for dinner, I became exhausted and told the Professor that since he was an older man I could not say what I wanted to him and I thought that he had an unfair advantage. Whereupon he said to go ahead and say what I pleased, which we both proceeded to do for another hour or so, but when I reached the Johns Hopkins Club after everyone had finished dinner, I found a group of my associates in the middle of an even more violent discussion about these molecules, which continued until well after midnight. When I arrived at the laboratory in the morning, a bit late after the efforts of the preceding day, Dr. Abel came into my room with triumph written all over his face and handed me a book, saying, "Read that and see if I'm not right." On looking it over, I found it to be a book on how to square the circle.

The laboratory lunch table became famous among the pharmacologists and visitors from many lands. Adjoining Professor Abel's laboratory was a fairly large room in which Dr. Rouiller had a chemical bench and in which Dr. Marshall was carrying out his experiments on the kidney. The lunch table itself was a small kitchen table covered with a white oilcloth, and, except for the Professor, who had a chair at the head of the table, we sat on laboratory stools. Charlie Kamphaus supplied us with a long roll of bread, some cheese, and "hot dogs" which I would not eat. This irritated the Professor greatly. He tried for years by every means he could think of to get me to eat them and usually ended his arguments by saying, "Oh, well, you are prejudiced, as all New Englanders are prejudiced." We made our own coffee. As far as I know, every member of the staff suggested at one time or another having something else for lunch, and the Professor always allowed him to try it, but every time we came back to the bread, cheese, and coffee luncheons, and all agreed that these were the best. We would have almost finished luncheon when Professor Abel would appear from his room, having removed his rubber apron but not his white hat. It was never more than a 
few moments before he would bring up some topic of conversation which was always interesting. He had an enormous amount of information about matters relating to his work as well as to the work of others, and he was always very much interested in historical matters, particularly in relation to the war. When we had such visitors as Sir Gowland Hopkins, Sir Henry Dale, Barger, and others who were working on biochemical problems, they would sit at the table half the afternoon going to the very bottom of these problems. But when we had visitors of other types who could not discuss fundamentals, the conversation soon lagged, and it became obvious that the Professor was anxious to get back to work.

There was nothing formal about these affairs or about the laboratory. We were usually surrounded by several dogs in a state of anesthesia due to paraldehyde, whose ureters had been cannulated by Dr. Marshall for his kidney experiments. The odor from the paraldehyde as well as the dogs was not too pleasing, but this made no difference. There were more roaches in that laboratory than in any place that I have ever been in, and I have been in bad ones. Several times we tried concerted gas attacks with sprays on these roaches and collected several buckets of them, but they came back almost at once. Then we tried putting the legs of the lunch table in tin cans of kerosene to see if that would keep the roaches out of our food, but even this was none too successful. The Professor always knocked his chair on the floor and shook out his coffee cup before sitting down. For years the coffee cups were Cross and Blackwell crockery marmalade jars. One day I noticed the Professor wiping his knife back and forth over the oilcloth on the table in a dreamy sort of way when he suddenly called out, "Charlie, Charlie, what is this? Haven't we got a new oilcloth?" When Charlie answered in the affirmative, he said in his far-off manner, "I thought so. I couldn't hear any roaches crackle underneath it." The roaches ate the backs off our books. They were so thick that anyone who had been in the laboratory any length of time automatically stepped back when opening a door to allow the roaches to fall, and we all turned the inside bands of our hats down before leaving for the night and shook the roaches out. I tried to clean the laboratory once and found that the drawers resembled the streets of Pompeii. They contained layers of papers and old notebooks between which rats had died, had become desiccated, and were flattened out by the accumulating material. By such excavations it was almost possible to tell the order in which Dr. Abel's assistants had come to the laboratory. It was only after a Spanish 
woman supplanted Mrs. Thomas as laboratory scrubwoman that we managed to clean the place up and get rid of the roaches by means of a roach food rather than a spray.

These remarks may sound a bit exaggerated, but it is a fact that when in fearful heat I was cleaning out the storeroom in the attic immediately under the roof on a very hot day with both Charlies, Charlie Drain was about to toss me a rather large, wooden box when Charlie Kamphaus shouted at him in a horrified manner and he stopped. It turned out that this was a box of T.N.T. which had been put aside and forgotten after a few experiments by Professor Abel. There was enough there to have removed not only the Department of Pharmacology but the entire Medical School as well.

A great deal of Professor Abel's charm was due to his intense interest in his work and, as I have said, his behaving as though everything that went on in the laboratory was on a plane far removed from everything else on this earth. I shall never forget his experiment on plasmapheresis which I saw when I first went to the laboratory. He had already carried out his preliminary work on dogs and asked me to join Dr. Marshall and Dr. Turner in further experiments which he wished to have done. Dr. Marshall was at that time an expert organic chemist with several years' training with Dr. Jones in biochemistry, but he had not yet had any pharmacology or medicine. Dr. Turner was a physical chemist from England who appealed to Dr. Abel's soul by calculating everything that went on, no matter what it might be. They had just bought a large centrifuge with which to centrifuge the blood taken from the dogs, and Dr. Turner proceeded to calculate just what would happen if the centrifuge should break while running at full speed. Each day, with his sleeves rolled up and a stop watch in his hand, he would push up the starting lever step by step, which took him the greater part of an hour, and calculate just where in Baltimore the different parts of the machine would land if things went to pieces. As Dr. Marshall and I were interested in getting these experiments done and as it took almost an hour to speed up the centrifuge, we were not so interested in these calculations, but the Professor, much to my surprise, put the utmost faith in them and told us never to use the centrifuge except under Turner's directions. Finally, we slipped in one day when Dr. Turner was away and found that speed could be obtained in from three to five minutes with perfect safety, a procedure which was adopted in the future.

After many preliminary trials Professor Abel decided to carry out one of his plasmapheresis experiments on a patient in the hospital 
who had nephritis, the idea being to remove a pint or so of blood at a time, add an anticoagulant, bring it back to the laboratory, centrifuge it, and replace the plasma with salt solution, returning the blood to the patient and repeating the process as often as it was necessary to do so. It was, of course, necessary to sterilize everything used for this work. I found that a physical chemist's idea of sterility was a curious one. Everything was passed through a flame, some slowly, others fast, depending on their nature, until they were "about sterile." Having collected a supply of this "about sterile" apparatus, we all repaired to the hospital. The patient was lying on an operating table with a donor next to him in case of accident, and the surgical benches were filled with interested spectators. A surgeon asked the Professor if he would not care to put on a cap and gown and take part in the experiment. Dr. Abel stepped up to the nurse and proceeded to get into his gown backwards, much to the consternation of the nurse. He finally got it on right side round, then his rubber gloves, and, on top of all, one of his much beloved operating caps. The Professor went about on tiptoe, talking in a hushed voice and watching the drawing of the blood with the greatest interest. During the first part of the time, he walked about with both hands high in the air, his mind centered on asepsis, but then he would see someone in one of the stands to whom he wished to speak, and would go over and take hold of the iron railing with both hands, and then come back to the operating table again with his hands held high in the air. It was difficult for those watching the experiment to restrain themselves under these circumstances, but they did extremely well. After the blood was drawn, Professor Abel rushed about in a very excited manner seeing that everything was ready to take the blood back to the laboratory, and in a low, excited whisper gave Turner directions as to just what to do. When all was ready, he disappeared out of the operating room, with both hands still high in the air. The moment the door closed there was a sigh of relief, but it was not more than thirty seconds after this when the Professor came rushing back still wearing his rubber gloves, his operating gown and cap, but with his derby hat stuffed on over it. Absolutely unconsciously he came up to the operating table, stood there talking very excitedly in whispers to the surgeon, and every few moments adjusted his derby hat with his rubber-gloved hands. About the time we all thought we could stand it no longer, he dashed out of the room after the blood, and on looking out of the window, we saw him tearing up Monument Street after Dr. Turner with his gown flapping in the wind, his derby hat on the back of his head, and his rubber gloves held high in the air. 
The laboratory course for the students was something never forgotten by anyone who took it. The course was given in a large laboratory with chemical benches all around the side, and two sets of these in the center of the room. I always tried to get the Professor to give the opening lecture in Pharmacology, and he would promise that he would, but on that particular day something would always come up, and as far as I can remember he never gave the lecture. He did, however, give a lecture occasionally, which was the cause of great excitement throughout the laboratory. Preparation on the lecture was put off until the last minute, and then everyone was sent rushing for one thing and another. The Professor would pull out from the top drawer of his desk a set of very ancient notes in which he would become deeply absorbed. He would send for twice as many articles as he could even look at in the time left before the lecture, and when the time finally did arrive, he was keyed up to such a state of excitement that his voice often broke and he told me, "The only way that I can lecture is to wait until shortly beforehand and then saturate my mind with material," but the result on the students was worth seeing. They instantly became absorbed in what he had to say or it may have been in the man who was saying it. In any case, they were unanimous in their praise of his lectures. Of course, at times he would give a special lecture on epinephrine, vividiffusion, or the pituitary, which he would prepare with very great care and exactness.

But to return to the laboratory course. There were laboratory exercises occupying one afternoon each week. Each year about two weeks before the course began, the two Charlies would go through the innumerable cupboards, drawers, research rooms, and so forth, and pull out what apparatus they could find for the laboratory experiments. Tambours, respiratory tanks, rubber tubing, cannulae, ether cones, kymographs were all put in a great heap on a large table in the corner of the laboratory with the idea of sorting these before the course began, but this was never known to have taken place. In another corner of the large laboratory there was a small research room which had been turned into a stock room in which the unlabeled bottles were kept, and this room had one of those doors which was cut across the middle so that the bottom could be kept closed when opening the top. About the time that the students began to arrive, the two Charlies would appear puffing up the three long flights of stairs with gunny sacks full of dogs on their backs, which were unceremoniously dumped over the half door into the 
corner room, but, like the apparatus, enough dogs were never brought up before the students arrived, so that half of the students would leave for the animal house and come trudging back with the dogs of all sizes, which were also dumped into the corner room.

There was a worse jam at the apparatus table than at a bargain counter, members of the different groups shouting when they found a tambour or some other necessary object which all four members of their group were looking for. The scene around the table took on the aspects of the stock exchange in a panic, members of the different groups diving into the meleé and signaling or shouting about the various parts of apparatus which they sought. It was the custom to shave the dog before operating, but there was only one razor for the entire class. Elaborate methods of matching or tossing a penny for the razor were devised to see who could get it first. When you dump a dozen unacquainted dogs into a small room after they have been tossed about in a gunny sack together, and let a crowd of excited students in to see who can get the best dog, the floor is not always in the best of condition, and after a student managed to get a dog, it made little difference to him what else he took to the big laboratory. After this preliminary fight and when the dogs were under ether, things quieted down for a bit until the injection of drugs began. The students attempted to obtain records of their experiments, using German roll paper kymographs, which one wound up with a key; the recording was done with the same red-ink pens as were used in research experiments. These kymographs must have been out of date when they were bought at the opening of the Medical School in 1893. It was impossible to make any of them run for any length of time, and you would hear a cheer from any group which managed to get a complete record of a single injection of a drug. The spirit of chance seemed to pervade the whole procedure in the laboratory. There was not only matching for the razor, the dog, and apparatus, but you would find different groups betting on whether their kymograph would or would not run through the next injection. In fact, as only half the class could take the course, there was a good deal of gambling on how to get into it, and I heard that at one time students were buying places for as much as twenty-five dollars.

When my turn came to take charge of the laboratory course, I went to Professor Abel and asked if I might not improve it a bit by buying new apparatus. Dr. Abel seemed quite hurt and said that as far as he could see, the course was all right. In those years he never came into the laboratory. However, as in all things, he was very 
cooperative and took me to the Dean, who was good enough to let me buy a whole new set of apparatus, a Harvard kymograph for each group, and later allowed me to put in a small shop and to obtain the services of an excellent machinist. Dr. Abel was not anxious to have the shop and tried to dissuade me by pointing out that there was no place to put it. When I suggested a corner of the large laboratory, he admitted that this would be all right and became quite despondent; but all of a sudden he remembered that the fire escape was right outside of the window where I proposed to put the shop, and he told me that it would never do to put it there. When I pointed out that there was already a chemical bench in front of this window as well as two shelves and three lines of pipes across it, which made it impossible to get out, he gave up and let me have the shop.

I spent a great deal of time on this laboratory course, systematized the whole procedure, and arranged for the entire class to take the course. I had drawers put in so that each group could lock up its own set of apparatus, and saw that a razor as well as the necessary apparatus for each experiment was supplied to each group. The result was very striking. Everything ran perfectly, the students obtained good records and went ahead in a very orderly fashion, and I was extremely proud of what I had done. But one day the Professor happened to come into the laboratory in the middle of the afternoon to ask me a question. In the midst of what he was saying, he suddenly stopped and looked around the room in a dreamy kind of way at the quietly working students and after a time said, "My goodness, Lamson, you certainly have ruined this course. The students used to have a good time here." There was much in this. Too much refinement can obliterate all initiative, but where the line is to be drawn is something for each generation to decide.

After my first year in the laboratory, during which Professor Abel was largely occupied with the writing of his Mellon lecture, I had a chance to see him at work on research. He became interested in secretin and with Dr. Pincoffs made more and more concentrated extracts of the intestinal mucosa until he obtained fractions that were rery active. Endless such fractions were separated, and each needed io be tested by its effect on the rate of pancreatic secretion in the dog. Dr. Pincoffs became very expert at preparing these animals. The pancreatic duct was cannulated, the trachea connected with an ether bottle, and the dog left to reach a state of equilibrium while everyone had lunch. Everything worked perfectly for a time, and then the dogs developed a peculiar habit of dying during the lunch 
hour. Everyone had his own idea as to why this happened. When they did die, they died at almost the same minute each day, but there were certain days on which they did not die at all. This became a problem of almost as much interest as the nature of secretin itself. It was solved, as many other things were in the laboratory, by Charlie Kamphaus, who discovered that the sun came around the corner of the building at the same time each day, shone on the ether bottle, and raised the ether concentration to a lethal level.

According to Charlie, it was also he who discovered the fact that the liver could concentrate phenoltetrachlorphthalein. Dr. Abel and Dr. Rowntree were working on this substance and studying its possible action as a cathartic. Charlie was cleaning up after one of Dr. Abel's experiments and was about to put the dog in a bucket when he noticed that this dye was pouring out of the bile duct which had accidentally been cut across. He called Dr. Abel's attention to this, and if what he says is so, and we could trust Charlie implicitly, we again have an example of an important medical discovery being made by chance, combined with the foreknowledge and altertness of the observer.

Although Dr. Abel's experiments on secretin, Witte's peptone, albumoses, and so forth, were painstaking and tedious, they were as nothing compared with his work on the pituitary. The preliminary pituitary extracts were made by Dr. Rouiller, Dr. Helen Graham, or Dr. Gelling and then worked up further by Dr. Abel himself. They were tested either on the blood pressure or on the guinea pig uterus or both, and here again the pharmacological tests were extremely simple and needed no complicated apparatus. By that time more modern methods of doing blood pressures had been introduced into the laboratory, and these were run off in great numbers. I well remember Professor Abel's great delight when he managed to get rid of a preliminary fall in blood pressure and obtained pituitary fractions which gave nothing but an instantaneous and beautiful rise of pressure.

The uterine experiments were carried out by Dr. Rouiller, who was a man for whom I had the utmost respect. He was an ideal person for Dr. Abel to have associated with him. He was not only an organic chemist of exceptional ability, but during the years in which he worked with Dr. Abel he was editing the Section on Organic Chemistry of Chemical Abstracts, and it seemed that there was nothing on earth of which he had not heard. It was Dr. Rouiller who convinced me that it was impossible to have an original idea. Every time I had one, it would not be two days before he would come quietly into 
my room, an open journal in his hand, and almost apologetically show me where this had already been done some time before. As far as I know, Dr. Rouiller never did anything but work, except to read on the streetcars to and from the laboratory. He was always there the first thing in the morning and, as far as I know, never left the laboratory until at least twelve o'clock at night. He had an even greater dislike than Dr. Abel for changing methods and an utter scorn for biological methods, particularly the one on which he worked for some eight or ten years to the exclusion of all others. This consisted in comparing the activity of Professor Abel's pituitary fractions with that of histamine by recording their effects upon the guinea pig uterus. Although Rouiller was a very quiet and self-contained person, what he had to say about the guinea pig's uterus cannot be recorded here. Anyone who knows these organs well, knows that it takes more than a saint to put up with their erratic behavior. They were strung up in a bath of Locke's solution and tied at one end to a writing lever, which needed to be constantly agitated so that it would not stick on the smoked paper of the kymograph. In order to produce this agitation Dr. Abel and Dr. Rouiller devised an apparatus consisting of a pencil stuck through the hole of a rubber stopper, and it was the experimenter's task to sit there and pound the desk with this rubber stopper, often for five or six hours at a time, while the uterus was trying to decide whether to behave itself or not. It was utterly impossible for me to convince either Dr. Abel or Dr. Rouiller that a mechanical agitator would work just as well, and I will admit that it was none of my business, but hammering a bench for hours at a time was one of those things which seemed to me to be obviously incompatible with the abilities of a great man.

For many years Dr. Abel carried out this work in spite of continued setbacks. He used to drop into my room at the end of the day and talk over his experiments while putting on his coat. Although at times he was discouraged, it was much more likely that he would say, "I've got it this time. I'll show it to you in the morning," but in the morning the fractions of which he had expected so much were apt to turn out in as disappointing a way as ever. This would never upset him, and he would begin all over again with as exactly as much enthusiasm as ever.

For a time Dr. Abel was assisted by Dr. Helen Graham, and as a sidelight on Dr. Abel's character it might be interesting to record a remark which he made about her. He said one evening to me, "Lamson, I have seen a good many women in science, and, to tell 
the truth, I have not felt that they were particularly well fitted for it, but Dr. Graham is different. She has upset all of my ideas on the matter, and she is as good if not better than any man whom I have ever had with me in the laboratory."

Anyone who has read Dr. Abel's work on histamine, the active principle of the pituitary gland, as well as his early work on epinephrine, must wonder why Dr. Abel published certain things that he did, why he was apparently in such a hurry about publication, and why he was so vague in his description of his work that it is almost impossible to repeat it. This seems incompatible with his critical judgment, the exactness which he required of others, and the standards which he set for his own journals. Personally, I think that it was Dr. Abel's terrifically intense interest in the outcome of his work which allowed him to do this. He was so interested in an absolutely honest way that this at times warped his judgment. I know that this was so about his conclusions of the part that histamine played in the activity of the pituitary gland. He would not listen to suggestions made to him by Dr. Marshall and others in the laboratory but dashed off this paper and published it without showing it to anyone.

It was very interesting to see the inner workings of The Journal of Pharmacology and Experimental Therapeutics at such times as when Dr. Abel got hot on the trail of something in which he was particularly interested. Before he reached the end, he would get more and more excited about his work and become suddenly convinced that he was going to settle everything the next day. He would call his secretary, ask for the publishers on the line, and have them hold the next number of the Journal until hearing from him. The entire laboratory would then be upset in an attempt to finish his work and rush a publication through. Every time the expected result was not found, and after a considerable delay of the Journal, Dr. Abel would reluctantly give the order to print the next number without his contribution. When a piece of work was really ready to be written up, the procedure was very different and involved weeks of poring over endless periodicals by Dr. Abel and his associates. Certainly no one would accuse him of having done this superficially.

I cannot go into details of the pituitary controversy, but after the finding that histamine was not the internal secretion of the pituitary gland and the finding by others suggesting that there were at least two, if not more, active principles rather than the one which he had postulated, Dr. Abel set out to show that his opponents could not be 
right. The discussions at the lunch table took on the character of a religious controversy, the Professor laying down the law about his unitarian doctrine and the absurdity of that held by the trinitarians. He insisted that it was the methods used by his opponents which gave them their multiple active principles. For years it has seemed that the Professor could not be right, but recent work indicates that there is a ray of hope for his doctrine.

In the previous sketches of Dr. Abel's life everyone has referred to how hard he worked. This, I think, can be gathered from what I have said already. During my stay in the laboratory Dr. Abel never spent the evenings there, for he was getting on in years, but I never dropped in on him at home but what I found him reading either history or something bearing on his work. I never saw him read a current novel. I have seen him work when he was so exhausted that he could hardly stand or speak above a whisper, particularly in the years after he had undergone an operation. At one time matters came to such a pass that he could not remember the names of anyone in the laboratory; he developed a very definite droop on one side of his face which made his speech indistinct, and I felt almost certain that if he kept on he would have a cerebral hemorrhage. I was unable to induce his clinical colleagues to talk to him about this, for they felt that it was interfering with his personal affairs, so I finally wrote the Professor a letter telling him just what I thought might happen to him if he kept on working as he was doing, explaining that if he should suddenly die, it would not be such a serious matter, but that if he were paralyzed, it would be. I also offered to resign from the laboratory if he did not wish to have someone around who was interfering with his life. Dr. Abel was indisposed on this day, and I left the note with Mrs. Abel at his house, wondering what the outcome would be. At about five in the afternoon Mrs. Abel called me, saying the professsor read my letter, remained silent for a few moments, and then said, "Mary, find out when the next train goes to Atlantic City." After a few weeks' rest he was a different person.

At this particular time Professor Abel had worked himself into a state of collapse over the matter of a biophysicist. He was then very much interested in the application of the infrared spectroscope to the analysis of his pituitary fractions. He was so impressed by the results of the experiments reported to him (although they were later found to be valueless, since they were not correctly obtained) and by the realization of the fact that those trained in physics might add as much to medicine as those trained in chemistry had already done, 
that he set out to bring about the organization of a department of biophysics in the Medical School. He encountered great opposition to his plan, which he attempted to overcome by sheer strength of character, but this failed, and his efforts nearly killed him. Many times he said to me that he was going to put this through if it was the last thing that he did in this world, but finally it was definitely settled that there would be no such department, and he went back to work once more. The success of such ventures in other places since has proven that there was more in what Dr. Abel suggested than was realized by his colleagues.

After his work on the pituitary he turned to the problem of insulin. $\mathrm{He}$, Rouiller, and Geiling worked as indefatigably on this as they had on the pituitary gland. In Dr. Geiling, Professor Abel found another devoted soul. Dr. Geiling gave up everything else in life for the Professor, as Mrs. Abel and Charlie Kamphaus both had done. He tested endless insulin fractions on rabbits, he looked out for all of Dr. Abel's affairs, both in and out of the laboratory, such as his traveling arrangements, his tickets, his taxicabs, and countless little things. He went with him to California for this work. He shared with Dr. Rouiller the terrible drives that Dr. Abel made on his problem, which always seemed to come at Christmas, Easter, or during the summer vacation, when one naturally wished to let down a bit, but in spite of Dr. Geiling's remarking that he wished the Professor could time these drives a little differently, he was always there, working with as great intensity as the Professor himself. Dr. Geiling was a very great help to Professor Abel in his latter years.

As said before, I have thought of Professor Abel as a mystic, someone whose mind was in the clouds and yet who was absolutely aware of what was going on in the particular field in which he was interested, whatever this might be, whether it was medical science, the war, or historical affairs. No one, whether it was a new assistant, one of his past associates, one of his colleagues, or a visiting foreigner, ever came into the laboratory without immediately feeling the friendship of this man and his real interest in what one came to see him about. If his visitor was of the first order, himself interested in some problem, the Professor would spend any amount of time discussing it with him regardless of his station in life. On the other hand it did not take but a few moments for Dr. Abel to recognize a second-rate man. He did not exactly like to turn such a man out but devised a convenient method of doing this. He would appear in my doorway with the visitor on his arm and would introduce him to me with the remark, "I 
want you to meet Dr. Lamson, who is doing some extraordinarily interesting work which I am sure he would be glad to tell you about," and with a wink of his one eye he would return to his laboratory. I would like to know how many such visitors I have had to dispose of for him in this way.

In his last years, time became the most precious thing for Dr. Abel. He would not relax but seemed to work harder than ever in the hope of accomplishing something in what he knew was an ever-diminishing period of time. He frequently spoke of hoping to last long enough to accomplish some particular object. We would take our manuscripts to him as Editor of The Journal of Pharmacology and Experimental Therapeutics, and although he was critical of outside publications, he assumed that the papers which we had written were worth publishing and he hated to waste time on them. I would go into his room with a manuscript, which he would take very graciously and with an air of intense interest. After opening it to one or two pages, or not at all, he would hand it back with a pat on the back and the remark, "That certainly is a fine piece of work. Just give it to our secretary, and we will put it in the next number," and even while handing it back, he would turn to his work once more. But if something needed attention, no matter what it was, he would drop everything for it. After I had been in the laboratory for about a year, I found that shutting off the arterial blood supply to the liver prevented the production of polycythemia after the intravenous injection of epinephrine, and I published this work in Dr. Abel's Journal. After returning to the laboratory I tried to repeat these experiments, and in the first two dogs which I used I was unable to do so. I was horrified at having published something from Dr. Abel's laboratory that was apparently not true, and decided that the best thing to do was to resign and get it over with as soon as possible, so I immediately went to Dr. Abel and told him what had happened. He listened to what I had to say with much interest, and to my utter surprise said, "But, Lamson, you must be right. Have you thrown away the dogs on which you carried out these experiments?" Such absolute confidence in an assistant not only endeared him to me for life but made it an absolute necessity that what I might do in the future must be well controlled. When I told him that I still had the dogs, he said, "You must have some collateral blood supply which you did not tie off." We went out to the laboratory, and he injected dye into the aorta, and sure enough in both instances the dye immediately went into the liver, showing that the blood supply had not been prop- 
erly cut off, and we were able to trace out collateral circulation. It was not only such trust and kindness as this but Dr. Abel's sympathy and understanding for all those who had the truth of things at heart that gave one faith, faith in the value of scientific ideals.

During the many years that I was with him I never heard Dr. Abel speak of trying to find a man for his laboratory or showing interest in promising young men who might make good pharmacologists. As far as I knew, men simply came there as I did, delighted with the opportunity of being allowed to work there. Everyone always seemed welcome, and a place was made for him. Dr. Abel's love of foreigners was obvious. Japanese, Chinese, South Africans, Englishmen, Swiss, Poles, and Spaniards worked there in even the few years that I was in the department. His recommendation to his assistants of new arrivals was the closest to falsification that I ever knew Dr. Abel to come. He brought me one man, for instance, whom he assured me would be of invaluable assistance, and introduced him as an expert biological chemist with a splendid training in medicine. This was a Spanish priest who, beside Spanish, spoke nothing but German and very little of that. I told this new associate that my work was on the liver, which seemed to interest him, and he confided to me that lie was a "non-conformist on the liver, that it was the cause of tuberculosis." When I asked him why, he replied that he would have to consult his notebooks, but they were in Spain. On getting to know him better, I found that he had had five years of lectures in chemistry and medicine but had never held a test tube in his hand or done a single experiment of any description. However, he turned out to be a most delightful person, of whom I became very fond.

With the exception of those who came to work with Professor Abel on his own problem, men were simply turned loose and allowed to sink or sivim. Some went through a great deal of mental anguish before finding a problem, but it was surprising how each did, how they absorbed the spirit of the Professor, and after a very short time were working day and night. One needs only to go over the list of those who worked in his laboratory and their accomplishments to see that whatever the methods of education were which the Professor used, they certainly were successful.

Finally, I should like to consider what Abel did for pharmacology, that special field of medicine for which he was responsible. It is often said that he paid no attention to organization, that he entirely neglected the training of his assistants as well as the students, and that in spite of his intense interest in research he let pharmacology 
run down. There can be no doubt whatever but that pharmacology did run down in this country during the latter years of Professor Abel's life, and it is also true that no effort was made by him, during the years that I was in his laboratory, to see to it that assistants were put through any sort of training or that a policy of any kind was carried out in relation to the student course. In fact, the Professor used to preach to me against spending too much time on lectures and the organization of pharmacology and advised me to put my efforts into research and let other matters take care of themselves. But was this not the reaction of a man who had been through much himself and had forgotten that others did not have the training which he himself had?

I do not feel that pharmacology would continue to exist as an entity if all departments were organized as Dr. Abel's was when I was there, for they would not be headed by Abels; but we must not forget that the state of pharmacology in his laboratory was more or less the fault of his assistants rather than of Dr. Abel. He had been through the years of effort which it took to develop the first pharmacological laboratory in this country, a series of lectures and demonstrations as well as laboratory experiments, the organization of a course not only in pharmacology but in toxicology, prescription writing, materia inedica, and dosage, and a course in pharmacy given by a group of the best pharmacists in this country. Anyone wishing to obtain an idea of the care with which he did this needs only to read his papers, "On the Teaching of Pharmacology, Materia Medica, and Therapeutics in our Medical Schools" (3), "Report on the Teaching of Pharmacodynamics, in the Report of the Committee on Medical Education of the American Medical Association" (4) and "The Education of the Superior Student" $(5)$. There were enough relics of these days in the Pompeian layers of the laboratory drawers to indicate what had been done in the past, but Dr. Abel's primary interest was not in organization. As soon as he had taken care of the organization of pharmacology in this country, not only in teaching but in the provision of a journal for the recording of experimental work and a society which would bring pharmacologists together, he left it to others to continue along the line which he had planned and himself turned to research, which he kept emphasizing as the basis of everything worth while.

We are apt to think of Abel as a biochemist rather than what many consider a pharmacologist to be. I know that Dr. Abel believed most thoroughly in the method employed by the pharmacologist of using the reaction of the organism in isolating active principles from plants 
and tissues. At the time when epinephrine and thyroxin were about the only hormones known, he felt that we had just made a beginning in the study of those processes of the body which are under chemical control. True it is that he was not interested in the superficial 'actions' of drugs, which are studied by many who are satisfied to go no further. His interest was in the 'nature of things,' the nature of the great chemical laboratory, the living organism. If he knew that something in some plant, some animal poison, some gland, or some bacterial toxin brought about a change when introduced into the body, he wanted terribly to know the nature of this chemical substance, as necessarily it must bear some relationship to one of the chemical constituents of the cell with which it reacted to bring about the secondary reactions observed, as changes in muscle tone, respiration, and so forth. Abel was as close to the bottom of things as one could go. He was a biologist of the most fundamental type. If one wishes to obtain in Abel's own words his concepts of these matters, they may be found in his presidential address to the American Association for the Advancement of Science (Science, 1934), as well as in his letter on pharmacology to Dr. Abraham Flexner, which is given in Dr. Voegtlin's biography of Dr. Abel (1, p. 397).

During the long life of a man such as Dr. Abel things are certain to change, and the problems of today are entirely different from those which he encountered in his most active years. If pharmacology has retrogressed since Dr. Abel began it in this country, those of us who have followed should not put the blame on him but on ourselves, possibly for not taking our share of the organization and the attention to general principles, which is necessary for the well being of any medical discipline, and perhaps more than for any other reason our failure to grasp just what was uppermost in Abel's mind as the function of the pharmacologist-the solution of the innermost chemical secrets of the living organism.

In all that is going on in the world today, with the utter chaos of thought, in spite of the terrific increase in scientific knowledge and technical ability, it is becoming more and more apparent that it is the man that is needed, rather than knowledge alone, the man with ideals and the courage to maintain them. But constructive ideals need knowledge, which can come only with study, training, and experience. All of these Abel had. It was this which made it possible for him to see what was best in medicine in his time, and what problems were of the most importance for investigation. Abel was ahead of his time in this country. His desire to get to the bottom of matters 
showed him the need of chemistry in medicine, and he took the time and staked his savings to get a training in chemistry before settling down to work. It was this which made it possible for him to see problems quite invisible to many of his colleagues and to visualize the coming of the present-day knowledge of hormones and the importance of chemistry in all life. He was equally well aware of the coming of physics in medicine but was unable to convince enough others of this to allow him to do for biophysics what he did for biological chemistry and pharmacology. When the life of this man is fully written, students of science as well as of medicine will do well to study it. Dr. Abel gave the world much by his investigations, but more than that he has given us ideals-lived up to-which anyone would do well to follow.

\section{REFERENCES}

(1) Clark, W. M.: J. Biol. Chem., 124, (n. p.) August 1938.

Dale, H. H.: Obituary Notices of the Roy. Soc. of London, 2, 577, 1939.

Geiling, E. M. K., And Evans, E. A., JR.: Scient. Monthly, 47, 185, 1938.

Geiling, E. M. K., And Evans, E. A., JR.: Arch. internat. de pharmacodyn. et de thérap., 60, 240, 1938.

Gunn, J. A.: Nature, London, 142, 242, 1938.

Marshall, E. K., Jr.: Science, 87, 566, 1938.

Voegtlin, C.: J. Pharmacol. \& Exper. Therap., 67, 373, 1939.

(2) AbeL, J. J.: Science, 42, 135 and 165, 1915.

(3) Abel, J. J.: Philadelphia Med. J., 6, 384, 1900.

(4) Abel, J. J.: A. M. A. Bull., 5, 54, 1909.

(5) AвеL, J. J.: J. Chem. Education, 7, 283, 1930. 


\title{
On the Blood-Pressure Raising Constituent of the Suprarenal
} Capsule*

\author{
JOHN J. ABEL, M.D. AND ALBERT C. CRAWFORD, M.D.
}

B the suprarenal capsule is an organ of vital importance.

Physiologists $\nmid$ have proved that a very small quantity of an aqueous extract of the medullary substance raises the blood pressure to a great height above the normal. It has also unequaled power in reviving a poisoned heart. Gottlieb, \& for example, has shown that it will revive the heart of a rabbit which has practically stopped beating in consequence of an intravenous injection of chloral hydrate.

Bates applied an aqueous solution to the eye and found that it exerted a marked vaso-constricting action. In numerous cases of congestion a small quantity dropped into the conjunctival sac brought about an immediate pallor, lasting for some time. According to this writer the extract is very useful in prolonged operations, for, when repeatedly applied, haemorrhage is prevented and cocaine anaesthesia is in consequence indefinitely prolonged. As the result of his two years' use of the extract Bates concludes "that within the limits of its sphere of activity there is absolutely no other substance which can take its place."

Other experiments $\|$ go to show that the aqueous extract is a powerful poison when injected directly into the circulation and may lead to fatal results.

* Read before the Association of American Physicians, May 6, 1897.

† Schäfer and Oliver, Journal of Physiology, xvi (1894) and xvii (1895); Szymonowicz and Cybulski, WVien. med. Wochenschrift, 1896, No. 6.

+ Arch. f. exp. Pathol. u. Pharmakol, xxxviii, 106.

$\$$ New York Medical Journal, 1xiii (1896), 647.

|| Foa and Pellacani, cited in Maly's Jahresb. d. Thier-Chemie, xiii, 129; MarinoZuco, ibicl., xviii, 231; Gourfein, Rev. Méd. de la Suisse Romande, Oct. 20, 1895; Compt. rend., cxxi (1895), 311-314. 
The various extracts that have been used in these experiments were mixtures of unknown substances, and it is as yet an unsolved question whether the various actions at present ascribed to the gland are due to one and the same substance.

We are at present interested in the isolation of the blood-pressureraising constituent, for in a purified state, separated from all other constituents, it might become a therapeutic agent of great importance.

On the chemical side but little advance has been made over Vulpian's* striking original contribution more than forty years ago. Vulpian observed that the juice expressed from the suprarenal capsule of many different animals behaved in a striking manner toward ferric chloride and toward solutions of iodine, giving with the former reagent an emerald green color, and with the latter a beautiful rose carmine tint. No other tissue of the body, so far as investigated by Vulpian, gave these reactions.

Virchow $\dagger$ substantiated Vulpian's statements, but added nothing new. A year after Vulpian's first announcement his second paper appeared in conjunction with Cloëz, $\ddagger$ verifying and extending his first observations and stating his failure to isolate the chromogenic substance or substances to which the above reactions are due.

Equally unsuccessful were Arnold $\S$ and Holm.\| Krukenberg,*** years after, repeated the work of Arnold and came to the conclusion that the chromogen of the suprarenal capsule is a non-volatile, nitrogenous and ferruginous organic acid which is probably related to the turacin of the musophagidae and to chlorophyll. He assumed that the substance giving the green color with ferric chloride is not the chromogenic substance of Vulpian, but more likely pyrocatechin accompanying the chromogen. Attention being thus attracted to the possible occurrence of pyrocatechin in the suprarenal capsule, others took up the subject.

Brunnert十 found that an alcololic extract can be made to give nearly all of the reactions of pyrocatechin; thus, it gives the wellknown green color with ferric chloride, passing into a fine red on the

* Note sur quelques reactions propres à la substance des capsules surrénales, Compt. rend. xliii (1856), 663-665.

† Virchow's Archiv, xii (1857), 481-483.

† Compt. rend., xlv (1857), 340-343.

§ Virchow's Archiv, xxxv (1866), 64-107.

Journ. f. prakt. Chemie, c (1867), 150.

* Virchow's Archiv, ci (1885), 542-591.

†† Schweizer. Wochenschr. f. Pharmacie, xxx (1892), 121-123. 
addition of ammonium tartrate and a few drops of an alkali; it reduces silver nitrate at room temperature, and Fehling's solution on boiling. The addition of an alkali soon causes it to take on a dark brown color, lead acetate gives a precipitate, nitroprusside and very dilute ammonia give a wine-red color. All of the above reactions being given also by pyrocatechin, Brunner concluded that Krukenberg was right in his belief that pyrocatechin is present in the suprarenal gland.

After the discovery of the blood-pressure-raising property of the suprarenal gland, B. Moore, * working in Schäfer's laboratory, came to the conclusion that Vulpian's chromogen and the blood-pressureraising constituent are identical. He based his opinion on the fact that chemical operations which destroy the color reactions by oxidizing the reducing agent appear also to destroy the blood-pressure-rasing constituent. That the solubilities of the active principle are the same as those of the reducing agent appears also to support this opinion.

Fraenkel $\uparrow$ worked with residues obtained with the help of alcohol and acetone as solvents. These residues raise the blood pressure and do not contain pyrocatechin, and on the strength of the ferric chloride reaction and its reducing power he concludes that the essential principle of the residue is a nitrogenous derivative of the orthodihydroxybenzene series.

According to Fraenkel both Krukenberg and Brunner are wrong in their opinion that the suprarenal gland contains pyrocatechin. Fraenkel concludes, like Moore, that the blood-pressure-raising constituent and Vulpian's chromogen are one and the same substance.

More recently still, Mühlmann + has attempted to prove that the blood-pressure-raising constituent is a pyrocatechin derivative. He asserts that on boiling fresh suprarenal capsules with dilute hydrochloric acid the active principle is decomposed and the pyrocatechin which is split off may be taken up with ether. Mühlmann has not, however, furnished conclusive chemical proofs for his assertion. Both Mühlmann and Brunner might have settled this point by precipitating the supposed pyrocatechin with lead acetate and analyzing the lead salt thus obtained. Pyrocatechin may be present in small amounts in the gland, but no proof of this has yet been furnished.

There is therefore at present great diversity of opinion as to the

* Journal of Physiology, xvii (1895), Proc. Physiol. Soc., p. xiv.

+ Wiener med. Blätter, 1896, No. 14-16.

† Deutsche med. Wochenschr., 1896, No. 26, 409-411. 
chemical character of the blood-pressure-raising constituent of the gland.

Whatever the probability may be of the correctness of this or that view, it is to be noted that all of the above-named investigators have based their conclusions on reactions made with aqueous, alcoholic or acetonic extracts; none of them have even roughly isolated a definite chemical compound. The subject is one of great difficulty, and our own work is at present merely preliminary, but we have arrived at the following conclusions which we believe to be borne out by our experiments.

First, we have found by isolating the blood-pressure-raising constituent in the form of a benzoyl compound and decomposing it, that the active principle is a substance with basic characteristics and that it must in all probability be classed with the pyrrol compounds or with the pyridine bases or alkaloids.

Second, that pyrocatechin cannot be split off from the isolated active compound by boiling with acids, as has been asserted.

Third, we have found that a carmine-red pigment can be separated from the sulphate of the active principle without destroying its power to raise the blood pressure.

Fourth, in addition to this, we have isolated from the crude benzoyl product a volatile basic body which fumes in the air and which emits an odor very much like that of coniine.

\section{Method of Isolating the Active Principle in the Form of a Benzoyl Compound}

We have used sheep's glands in large quantity. The medullary substance of the fresh glands was scraped out, dried on the water-bath at $60^{\circ} \mathrm{C}$., ground up finely, and extracted with ether for several days until the fats and the substance known as Manasse's jecorin were removed. In this way a fine dry powder of a grayish white appearance is obtained, the aqueous extract of which is very active in raising the blood pressure.

With 100 grammes or more of this powder, representing one $\mathrm{kg}$. in weight or about 1000 fresh glands, we proceeded as follows: The powder is repeatedly extracted with warm water acidulated with a few drops of dilute sulphuric acid until the gland has yielded up all of its chromogenic substances, as tested by Vulpian's reactions. This aqueous extract is evaporated on the water-bath to a small bulk, a large excess of strong alcohol is then added and the whole allowed to stand 24 hours, by which time the proteids have all settled out. The 
alcoholic fluid is then filtered and the greater part of the alcohol removed by distillation; the remainder is driven off on the water-bath. The entire removal of the alcohol is necessary, and in order to avoid too great concentration of the acid fluid, which seems to destroy some of the active principle, water has now and then to be added. The brownish fluid when filtered gives all the well-known reactions characteristic of Vulpian's chromogen, and on neutralizing the sulphuric acid we found the filtrate to be physiologically very active.

This filtered fluid is next treated with the proper quantity of benzoyl chloride and sodium hydrate according to the BaumannSchotten method of forming a benzoyl compound. There results a tarry substance of a light yellow color which sticks to the sides of the separator funnel and which is collected and washed until the wash Huid no longer gives an alkaline reaction. It is next dissolved as far as possible in alcohol and the alcohol evaporated. The residue is then treated with ether, which takes up the greater part of it, the ethereal solution is filtered and the ether driven off.

The residue, which is of tarry consistence and amber color, is taken up in strong alcohol from which all basic substances have been removed by distilling from tartaric acid. It is then boiled for two hours with animal charcoal previously well washed with purified alcohol. After filtration and the evaporation of the alcohol a considerable quantity of crystalline residue is obtained which is found to consist of the benzoyl compound of the active principle contaminated with other benzoyl derivatives and which we may call the crude benzoyl product. It is insoluble in water, alkalies or acids of ordinary strength, is soluble in alcohol, ether, glacial acetic acid and concentrated sulphuric acid.

It is of interest in this connection to note that benzoyl chloride effects the complete removal of the blood-pressure-raising constituent from an aqueous solution. This is proved by the fact that the filtrate from the insoluble benzoate no longer gives the characteristic chemical reactions of the active principle, and that chemical manipulations no longer yield a blood-pressure-raising constituent. Indeed, an injection of a sufficient amount of the material left after the sodium benzoate and the excess of alkali have been removed, causes a sharp and sudden fall of pressure instead of a rise.

It was not until long after we had made use of benzoyl chloride as a precipitant of the active principle that we obtained access to Fraenkel's* paper. From it we learned that a syrupy substance is

* Wien. med. Blätter, 1896, No. 14-16. 
thrown out when benzoyl chloride is shaken up with a pyridine solution of an extract of the gland. Fraenkel did not succeed in crystallizing this benzoyl compound, nor did he attempt to decompose it in order to ascertain whether it was in reality a benzoate of the blood-pressureraising principle.

\section{Methods of Decomposing the Benzoyl Compound}

A quick method always used by us as a qualitative test is as follows: The compound is dissolved in as little concentrated sulphuric acid as possible, crushed ice is slowly added, and the benzoic acid which has been split off is shaken out with ether. On neutralizing the solution we found it to give the reactions characteristic of aqueous solutions of the medullary substance. We have not considered this method adapted to the decomposition of large quantities of the product.

Decomposition of this benzoyl product was effected by means of an alcoholic solution of sodium alcoholate, and also with strong hydrochloric acid and alcohol, but these methods were found to be less satisfactory in practice than the following, which is the method on which we now rely. The benzoyl compound is dissolved in glacial acetic acid, the solution heated to near the boiling point, and an equal volume of a 25 per cent solution of sulphuric acid actively boiling is slowly poured into the hot acetic acid solution, the whole being shaken meanwhile. The flask is now attached to a back-flow condenser and heated on a small flame for about ten minutes.

The solution is next diluted with water and allowed to cool, the benzoic acid, which has been thrown out, is filtered off and the rest is removed with the help of ether.

Mixed with the benzoic acid which has been removed by filtration is found a dark brittle substance which softens on the water-bath, and which we assume to be a benzoyl compound of unknown composition which was apparently unaffected by the dilute sulphuric acid. On dissolving it in concentrated sulphuric acid and diluting with crushed ice, the resulting fluid gives none of the reactions characteristic of suprarenal extracts.

After decomposing the benzoyl product with hot dilute sulphuric acid and removing the benzoic acid thus split off, we next get rid of the acetic acid by repeated partial evaporations, taking care not to let the solution become too concentrated and thus perhaps injure the active principle. After the removal of the acetic acid the sulphuric acid is precipitated with the help of lead carbonate. The lead sulphate is removed and the filtrate is allowed to stand in vacuo over 
sulphuric acid until it has become of tarry consistency. It is then exhausted with ether, acetone and absolute alcohol in succession.

The residue is physiologically very active, and it gives all the reactions characteristic of an aqueous solution of the gland-a beautiful rose color on the addition of an alkali, a green color with ferric chloride, reducing silver nitrate, etc.

However, we are not yet dealing with a pure substance. If we neutralize an aqueous solution of the product thus obtained with a free alkali or with a carbonate of the alkalies, an overpowering odor much like that of coniine is perceived. As this odor passes that of pyridine seems to take its place. The basic substance thus liberated fumes in the air or when a glass rod moistened with hydrochloric acid is brought into its neighborhood. To remove this basic substance we made an aqueous solution of the active principle as above isolated, rendered it faintly alkaline with sodium carbonate and shook out ether several times in succession. But this method does not remove all of the coniine-like substance. To effect this we were obliged to make the active principle strongly alkaline with sodium hydrate before shaking out with ether. The aqueous solution, in consequence of the addition of the free alkali, takes on a deep red color, and carmine red flocks are thrown out. After the removal of the coniine-like substance with ether, the fluid containing the red flocks was acidulated with sulphuric acid and the carmine-red substance was filtered off. The clear filtrate, which was a pale straw color, was concentrated in vacuo, and the active principle taken up in weak alcohol. On account of the insolubility of the sulphate of the active principle in absolute alcohol it is difficult to obtain this entirely free of sodium sulphate. We hope in future to remove both the coniine-like substance and the pigment with the help of ammonia. The presence of pyridine in our ammonia prevented our using it for this purpose.

This volatile base of a coniine-like odor has not hitherto been described as a constituent of the suprarenal capsule. The beautiful carmine-red pigment we take to be identical with the red substance which many other observers have found to be thrown out as a precipitate when ammonia is added to a concentrated aqueous solution of the gland, or when a solution is evaporated in the presence of lead acetate.* Others have believed this red precipitate to be the oxidation product of the active principle of the gland, but we shall presently see that the active principle is still present in the filtrate from the

*Holm, Journ. f. prakt. Chemie, c (1867), 150. 
carmine-red body. We have as yet made no experiments with this pigment except to note that it is but slightly soluble in dilute alkalies and insoluble in dilute acids, and that iodine destroys the color. Our method appears to make the further study of this substance possible.

The coniine-like substance we have secured in the form of its hydrochlorate, and with it we have made certain studies which will be published at a later date.

\section{Characteristics of the Blood-Pressure-Raising Constituent}

AS OBTAINED BY DECOMPOSING ITS

\section{Benzoyl Compound}

We have now obtained the active principle in the form of a sulphate. As thus far isolated it is a hygroscopic, straw-colored residue which tends to crystallize on standing over sulphuric acid, agglomerates of small crystals forming on the edge of the bowl and the entire residue taking on a semi-crystalline appearance. This sulphate does not contain the volatile coniine-like substance, nor do we find the carmine-red pigment which falls out on the addition of an alkali. Alkalies no longer liberate the coniine-like substance, nor do they throw out the red pigment, but they cause a brownish discoloration, and on heating, alkaline vapors, probably ammonia, are given off.

Our sulphate is very active physiologically. A small quantity suffices to raise the blood-pressure and it is therefore evident that we have isolated the active principle but slightly contaminated with other substances.

A final product even more active in small quantities is that whose action is shown where the mercury is driven out of the manometer. This more active compound still contains much of the coniine-like substance, and at once throws out the carmine-red pigment on the addition of alkalies. The sulphate of the coniine-like substance does not, as we have seen, raise the blood pressure; it therefore remains for us to consider whether the carmine-red substance which is precipitated on the addition of alkalies, either alone or in conjunction with small quantities of oxidizing agents, has any physiological significance or stands in any chemical relation to the blood-pressureraising constituent. We incline to the opinion that this substance, which in the original aqueous solution of the gland gives with iodine water the "teinte rose-carmin tout à fait remarquable" of Vulpian, is in nowise connected with the blood-pressure-raising constituent. We have repeatedly removed or destroyed this substance by boiling solutions containing it with strong ammonia or with sodium hydrate, 
and have always been able to separate subsequently an active material. After such treatment with alkalies, care must be taken in the subsequent evaporation of the alcohol with which the active principle is removed, to keep an acid reaction, as otherwise the greater part, if not all of it, will be destroyed by oxidation. And unless all evaporations are carried on under reduced pressure, much material will be lost, eren with the above precaution.

Although somerwat contaminated with its own decomposition products, this final sulphate has all the characteristics of an active substance. As shown by repeated experiments, it promptly raises the blood pressure, it constricts the vessels of an inflamed eye, and when injected into the dorsal lymph sac of the frog it acts like a narcotic or cerebro-spinal poison.

As freed of the red substance the sulphate of the active principle behaves as follows: It is very soluble in water, fairly soluble in weak alcohol ( 50 per cent), almost insoluble in absolute alcohol, and quite insoluble in ether, acetone, ligroine and chloroform. Its aqueous solution, even when freed from adherent sulphuric acid, has a slightly acid reaction. The addition of iodine water to a neutral solution does not give a rose-red color. Alkalies added to a strong solution give a brown color which deepens on heating. Ferric chloride gives a purplish brown, almost black in concentrated solution, which on the addition of tartaric acid and an alkali passes into a deep red color. Before the removal of the carmine-red substance the addition of ferric chloride gives the well-known emerald green color, which passes into red on the addition of an alkali.

It is evident that our sulphate gives Vulpian's ferric chloride reaction, though somewhat changed by the removal of what we take to be the chromogenic substance which gave his iodine reaction. It also promptly reduces silver nitrate in alkaline solution, but does not reduce Fehling's solution even on boiling.

\section{Probable Relation to the Alkaloids}

More than a year ago, during our first studies with suprarenal extract, we were struck with the fact that every extract entirely free of proteids and physiologically active gave a fine pyrrol reaction when subjected to dry distillation. This is evidenced both by the odor and by the pine sliver reaction. A small quantity of the isolated sulphate also gives the pyrrol reaction when heated either alone or with zinc dust.

We attach considerable importance to this reaction. As is well 
known, alkaloids in general give pyrrol on dry distillation; morphine, for instance, on being heated with 10 parts of zinc dust gives off pyrrol, ammonia, trimethylamine, pyridine, phenanthrene, etc.* During the past winter we made several attempts to prove the presence of pyridine among the products of dry distillation of the active principle as above isolated, as its detection would prove that our principle was to be classed among the alkaloids.

In attempting to show the presence of pyridine we heated the active principle with zinc dust in a current of dry hydrogen and passed the distillation products through a test tube and two small flasks, the tube being placed in a cooling mixture, the first flask being partly filled with dilute sodium hydrate, and the second with dilute hydrochloric acid.

At the close of the experiment the test tube gave off alkaline vapors that smelled strongly of trimethylamine and had in addition a peculiar sweetish odor. The contents of the test tube diluted with water gave a precipitate with bromine water and with copper sulphate, but with the latter reagent the fine blue color characteristic of pyridine did not appear. The presence of amines seems to render difficult the detection of small quantities of pyridine. The contents of the third flask on exposure to the air took on a rose-red color and after a time threw out a precipitate of the same tint. Both flasks gave off the odor of benzaldehyde.

The following experiment was also made with a little of the sulphate, which no longer gave the rose-red reaction with iodine but which still contained a little of the coniine-like substance. For two hours it was kept at $150^{\circ} \mathrm{C}$. in a sealed tube with 25 per cent hydrochloric acid. On shaking out with ether a considerable crystalline residue was obtained which, without much purification, melted sharply at $120^{\circ} \mathrm{C}$. and had all the properties of benzoic acid.

In the above decomposition experiments the quantity of material at command was small, perhaps not more than one-fifth of a gramme at a time, and not entirely pure. We do not, therefore, lay much stress on our failure to detect pyridine.

The fact that the nitrogen of our compound is given off in the form of amines and pyrrol gives strong ground to believe that our substance is to be classed witl the pyridine bases, using this term in a broad way. Its basic character, its ability to take up acid radicles, as illus-

* We are well aware that certain salts of glutaminic, pyromucic and its related acids also yield pyrrol on dry distillation. These compounds, however, like the proteids and their allies, appear to us to be excluded. 
trated by the formation of a benzoyl product, its reducing power and its color reaction with ferric chloride are all points which can be urged in support of this view. Furthermore, cupric acetate, the serviceableness of which as a precipitant of carbo-pyridine bases has been shown by Gautier and Landi,* also precipitates our active principle; and iodine chloride, which Dittmart found to give brown or yellow halogen addition-derivatives with a large number of the alkaloids, gives with a neutral or slightly acid solution of our active sulphate a brownish flocculent precipitate.

Of less weight in this connection, but nevertheless of some value, is the fact that its physiological action and its power in small doses is again in accord with what is known of alkaloids. Strychnine, thebaine and other alkaloids are readily called to mind as able to raise the blood pressure, and recently Tunnicliffe + has placed piperidine in the same list. The pyrrol§ bases are also physiologically active, although less attention has been paid to them.

\section{PyROCATECHIN CANNOT BE SPLIT OFF FROM THE Blood-Pressure-Raising Constituent}

As already said, Mühlmann has stated with great positiveness that the blood-pressure-raising constituent is pyrocatechin joined to some other substance, probably an acid. Mühlmann does not offer sufficient proof for his conclusion; and even had he proved the presence of pyrocatechin in the gland itself, this is a very different thing from showing that it enters into the chemical constitution of the bloodpressure-raising constituent.

We have repeated Mühlmann's work and have found that after boiling the medullary substance with hydrochloric acid, the ether takes up a trace of Vulpian's substance, as well as a substance that reduces Fehling's solution.

The ether residue also gives a precipitate with neutral lead acetate which, on decomposition with dilute sulphuric acid, sets free a compound that gives with ferric chloride the reaction so characteristic of pyrocatechin. Our blood-pressure-raising constituent is not precipitated by lead acetate and could not, therefore, have been responsible for this result.

* Compt. rend., cxiv (1892), 1154-1159.

+ Berichte d. deutsch. chem. Gesellsch., xviii, 1612.

† Centralbl. f. Physiol., x, No. 25, 777.

§ Jac. Ginzberg, Ueber das Verhalten des Pyrrols, etc., Inaug. Diss., Königsberg, 1890. 
Furthermore, on decomposing a fairly large quantity of the crude benzoyl product before referred to and shaking out the resulting benzoic acid with ether, we have twice found that the ether has taken up in addition to the benzoic acid a small quantity of a substance which reduces Fehling's solution and gives a precipitate with neutral lead acetate. On decomposing the resulting lead compound with dilute sulphuric acid and neutralizing the filtrate, we obtained a solution which behaved with ferric chloride in the way characteristic of pyrocatechin. The quantity of this lead compound obtained has been too small for analytical purposes.

We consider it, therefore, still uncertain whether or not a little pyrocatechin is present in the gland.

That the blood-pressure-raising constituent is, however, not a pyrocatechin derivative seems to us certain. To prove this we used, not the entire gland nor the medullary substance, but the active principle itself, as isolated by us by decomposing the benzoyl compound.

We have used large quantities of material representing in each experiment the active principle of several thousand glands. We have boiled this with hydrochloric acid of varying strength and for varying lengths of time, and in no case have we been able to find in the ether used as a solvent any trace of a substance that would reduce Fehling's solution or give a precipitate with lead acetate. Inasmuch as some of the chromogenic substance always passes into the ether from acid solutions, these two reactions are both necessary to establish the presence of pyrocatechin. In other words, we have failed to split off pyrocatechin from the active principle as isolated by us. If present, it could hardly have eluded our search, for even a minute quantity may be made to give a precipitate with neutral lead acetate.

We propose during the coming autumn to continue this work. Having made arrangements for the use of a large amount of material, we hope to secure both the benzoate and the sulphate in a form pure enough for analysis and for further chemical study.

\section{SUMMARY}

We may summarize the results of our work as follows:

The blood-pressure-raising constituent of the suprarenal capsule may be completely precipitated from an aqueous extract by treatment with benzoyl chloride and sodium hydrate, according to the Schotten-Baumann method.

On decomposing the resulting benzoyl products, a residue is obtained which possesses great physiological activity. It gives the color 
reactions of V'ulpian, reduces silver nitrate and possesses the other specific qualities of suprarenal extracts.

IVith the help of alkalies a carmine-red pigment may also be separated from these decomposition products. We take this pigment to be that one of the chromogenic substances of Vulpian which gives the rose-carmine color when suprarenal extracts are treated with oxidizing agents or alkalies.

$A$ volatile, basic substance of a coniine-like odor is always found to accompany the crude benzoate. When these substances are removed the active principle is left as a highly active sulphate or hydrochlorate, as the case may be. It is therefore a basic substance. Its salts give a color reaction with ferric chloride; they also reduce silver nitrate, but not Fehling's solution.

It is not possible to split off pyrocatechin from this isolated active principle. The fact that dry distillation causes the appearance of amines and pyrrol in abundance, taken in connection with its ability to take up acid radicles, its reducing power, its precipitability by cupric acetate and iodine chloride, and its physiological action, lead us to conclude that our active principle is to be classed with the pyridine bases or alkaloids.

\section{Addendum, June 15, 1897}

Since the foregoing paper was read before the Association of American Physicians on May 6, 1897, B. Moore has published a paper in the Journal of Physiology, vol. xxi, Nos. 4 and 5, May 12, 1897, entitled, "On the Chromogen and on the active Physiological Substance of the Suprarenal Gland." In this paper it is suggested that the active principle may be a pyridine derivative. Moore's conjecture is based, first, on a formula calculated by him from a combustion analysis of Krukenberg, made with an impure, hygroscopic, noncrystalline residue obtained by merely decomposing and drying a precipitate secured out of an alcoholic extract of the gland with the help of basic lead acetate. The calculated formula, the carbon content of which differs by 1.33 per cent from that actually found by Krukenberg, is $\mathrm{C}_{5} \mathrm{H}_{14} \mathrm{NO}_{4}$, and Moore points out that in it the ratio in which the elements carbon and nitrogen stand to each other is the same as in pyridine, $\mathrm{C}_{5} \mathrm{H}_{5} \mathrm{~N}$. Now such a calculation, though suggestive to the investigator, furnishes no proof of the presence of pyridine, for Krukenberg could not possibly have had in hand a chemical individual uncontaminated with other constituents of the gland. Krukenberg himself admits that his material was a mixture of unaltered pigment and its decomposition prod- 
ucts. It is also certain that it was contaminated with other constituents of the gland. This is proved by the fact that basic lead acetate precipitates several of the constituents of the gland which pass into alcohol, and also by the fact that the analyzed material contained 0.068 per cent of sulphur and from 1.18 per cent to 1.44 per cent of ash.

A second reason given by Moore in support of his conjecture is that when "some suprarenal extract was cautiously fused with caustic potash so as to avoid charring, the peculiar odor of pyridine was at once obtained." He admits that proteids were present in this extract, and that pyridine and its homologues are formed in the destructive distillation of proteids, but states that the experiment was "conducted so as to avoid charring," and considers this a sufficient safeguard. This experiment has also no value, for the odor of pyridine can always be obtained when a mixture of dry, powdered proteid and porvdered caustic potash are fused together so as to avoid charring. This experiment, therefore, must be made with material entirely free of proteids. Since reading Moore's paper we have fused a little of our active principle with caustic potash, but have failed to detect pyridine. If present in the molecule of the active principle, it is evident that larger quantities of the material must be used to prove it. Only indisputable chemical proofs can establish the presence of pyridine; the odor is not enough. We have frequently in various manipulations with the active substance met with what we took to be the odor of pyridine, but on shaking out with ether and adding an ethereal solution of hydrochloric acid and evaporating the ether we have been unable to detect pyridine in the residue. 


\section{On the Teaching of Pharmacology, Materia Medica, and Therapeutics in Our Medical Schools}

JOHN J. ABEL, M.D.

$\mathbf{I}_{1}$

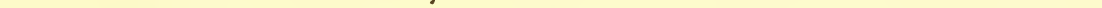
journal what is meant by pharmacology, but the frequent confusion of this term with pharmacy by those who are not teachers of medicine must serve as a reason for a brief statement of the methods and aims of this branch of medical science. The vague and often erroneous use of the word pharmacology seen in earlier writings, as in the definition of Nathan Bailey (1736), "a treatise concerning drugs," or in that of Samuel Johnson (1755), "an equivalent of pharmacy or pharmaceutics," is still frequently met with in our own time. Briefly stated, pharmacology tries to discover and explain all of the more obvious functional, and the less noticeable chemical and physical changes that occur in a living thing that has absorbed a substance capable of producing such changes, and it is also its province to learn the fate of the substance thus incorporated. It is not, therefore, an applied science like therapeutics; it is one of the biological sciences, using that term in its widest sense.

The interested student of the history of medicine discovers in every epoch some man far in advance of his contemporaries who may be looked upon as a leader in one phase or another of our subject. Such were Erasistratus, Dioscorides, Mesua, Avenzoar, Paracelsus, and Haller; and when we turn our attention to the modern laboratory methods of pharmacology and the lasting achievements gained by their aid, we find that the first great impulse was given by Magendie. That great experimenter's classical research on the physiological action of upas, undertaken early in the present century, was the first instance of the completely successful application of the analytic method in the 
study of the coarser changes of function which follow on the use of drugs. As early as 1813 he had also proved that the blood is capable of taking up and carrying metallic poisons, but it was not until the middle of the century that the pernicious doctrine of the "action of poisons by sympathy" received its death-blow. About the middle of the century, too, the memorable experiments of Claude Bernard and of Kölliker proving that the paralyzing action of curare centers in the end plates of the motor nerves gave further evidence of the value of physiological analysis as applied to the study of drugs.

Brilliant discoveries of a similar character have followed from time to time, and we have now innumerable instances of the rational analysis and at least partial comprehension of the more obvious functional changes that follow upon the administration of drugs and poisons. One has but to recall atropin, pilocarpin, muscarin, eserin, cocain, digitalis, amyl nitrite, chloral, chloroform, ether, salicylic acid, ergot, and other well-known drugs and poisons, to appreciate how great is the store of knowledge relating to the action of drugs which is at the disposal of the modern student.

It was experiments like those of Magendie and his successors that induced Mitscherlich (1847) and later Buchheim, to insist on the insufficiency of the mere bedside study of the action of drugs and led to the erection of special laboratories in which experimenters can build up their science undisturbed by the intrusive demands of practical utility. Buchheim's pharmacological laboratory founded at the University of Dorpat in 1849, was the first public institution of the kind in the world and was long the best equipped in Germany. But it was not alone in Germany that attention was called to the new methods. The medical literature of our own country contains some eloquent pleas in favor of the analyses of medical problems by means of experiments. From among these I would call attention to that of Dr. R. Cresson Stiles, contained in a worthy but little-known research, published in 1865, entitled: On the Direct Influence of Medicinal and Morbific Agents upon the Muscular Tissues of the Bloodvessels. This physician was interested in the problem as to how the blood, in febrile conditions, acts upon the circulatory mechanism. He evinced considerable experimental skill, as shown by his use of the "surviving" umbilical artery in his transfusion experiments, and he seems to have had some premonitions of our later theories, for he subjected the umbilical artery to the action of blood drawn from a patient with typhoid fever and compared the results thus obtained with those noted when normal blood was used. 
In one part of his paper he defends and justifies his methods in the following words: "Moreover, it is not to mere clinical experience that we must look for a revelation of the laws of disease. The laws of chemistry were not discovered in blazing fires or crumbling rocks; the laws of hydrostatics and hydraulics were not revealed in torrents, tides, or ocean currents, nor those of pneumatics and electricity in winds, whirlwinds, and thunderstorms; much less could it be rationally expected that the laws of pathology should be discovered amid the much greater complexity and more multitudinous conflicts of elements presented to the physician at the bedside of a diseased or dying patient. It is in the laboratory, and by artifically contrived experiments that the clue has ever been spun and the torch lighted to guide through the labyrinths which hide the arcana of nature."

By means of "artificially contrived experiments" we are today enabled to demonstrate in detail how drugs act on the various organs of the body and what is their immediate, specific action on the parts of a compound mechanism like the circulatory apparatus. Thus we teach the student of our day the method by which is analyzed the action of a drug on the heart and arteries, on the vasomotor, cardioinhibitory and respiratory centers, on the terminals of the vagus, on the spinal cord and brain, on the intestines, the uterus, the salivary and other glands, the iris, ciliary body, etc. Conceptions familiar to the therapeutician are thus resolved into their elements and made accessible to the beginner.

The empiricist may perhaps assert that an experimental demonstration and analysis of the manner in which atropin, for example, causes dilation of the pupil is of little service to him, that the clinical fact is all-sufficient. A physician of this practical turn of mind may long use with safety his corrosive sublimate, his ether, his salicylic acid, his homatropin, eserin, and other drugs; but, sooner or later, if he is an observing man, he will find himeslf confronted by doubtful and obscure questions which directly concern the welfare of his patient, questions that can only be cleared up with the help of the "artificially contrived experiment." No branch of practical medicine can afford to neglect the study of the principles and methods of pharmacology. For, like other branches of experimental science, it teaches conservatism by pointing out how vastly complex are the phenomena of the action of drugs and showing how little is clearly understood aside from the grosser and visible changes which follow upon their ad ministration. The dogmatic use, in symptomatic treatment, of cardiac stimulants, depressants, antipyretics, and innumerable other remedies

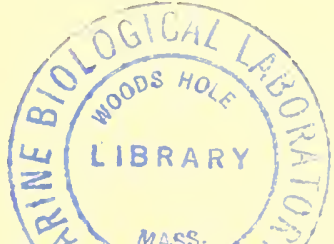


whose extraordinary virtues are lauded in commercial circulars, finds no justification in the teachings of pharmacology. Its teachings are not always or immediately convertible into bedside dogmas.

It must be confessed that the therapeutic nihilist who uses only what is indispensable among drugs, but who is wise in the curative power of air, water, food, rest, and exercise, will have less to answer for in the final reckoning than his drug-enslaved colleague who prates of controlling disease in its every symptom with this or that panacea and who is guilty of the premature application to practice of what are only unproved theories.

Pharmacology gives no support to the unthinking worship of canonical authority. In instances when true specifics and well-founded remedies are manifestly powerless, the plan outlined by John Locke is as applicable now as it was when he wrote: "You cannot imagine how far a little observation carefully made by a man not tied up to the four humours, or sal sulphur and mercury, or to acid and alkali, which has of late prevailed, will carry a man in the curing of diseases though very stubborn and dangerous; and that with very little and common things, and almost no medicine at all."

In an age which pathology and diagnosis are so far advanced and in which more genuine help is derived from the rational use of drugs than ever before in the history of medicine, haphazard drugging is unpardonable, and still more to be condemned is a fanatical and conceited adherence to dogmas based on a superficial understanding of complex physiological principles.

I have spoken thus far only of the older and well-tried methods of pharmacology, methods that are still fruitful, although newer tendencies are now followed and fresher fields are being tilled. The more detailed examination by means of modern physiological methods of the respiratory, circulatory, muscular, nervous, and other functional derangements which are met in "intoxications" will surely lead to most important results. One of my younger colleagues, who is now carefully reviewing the list of drugs that act on the heart, tells me that not a single one of them has been studied on all sides from a modern physiological standpoint. Digitalis alone of the list has been the object of a fairly complete physiological examination, but everywhere in this field of the cardiaca there seems to be a great accumulation of physiological facts ready for the coordinating hand of the pharmacologist. As elsewhere, judgment and special knowledge are required, and the day has long passed when he who knows the drugs of the pharmacopeia and their clinical uses and who is able only to 
set up a kymograph and attach a few registering instruments can claim to be a pharmacologist. Such an one will not travel far beyond the region of mere routine, a region chiefly of pedagogical interest.

Thoughtful pharmacologists have also made it the object of their investigations to understand more fully the chemical and chemicomolecular phenomena that underlie and accompany the coarser changes to which reference has already been made. The principles of physics and chemistry must furnish the pharmacologist with provisional or permanent explanations of these phenomena. Like the physicist, he is well aware, however, of the "futility of attempting an ultimate explanation of natural phenomena," and fully recognizes the limitations of his method. At present we make use of a hundred terms which convey anything but a clear idea to the mind. Take so old a drug as ethyl alcohol, for example, and endeavor to explain why it is not a dynamogenic substance for muscle-tissue. We hide behind such expressions as "protoplasm poison" and the like. We know that alcohol is oxidized in the tissues and that liberation of energy follows, but a more careful study of the subject shows that oxidizability and the liberation of energy are not alone the measure of dynamogenic value. A closer study of the intermediate steps in the oxidation and of the chemico-molecular processes which are initiated by these products and by the alcohol itself will alone clear up a problem of this sort.

Knowledge of the "chemical architecture" and constitution of a given drug often enables the pharmacologist to trace it in its passage through the body, and in studying its chemical fate and final disposition, valuable facts bearing on the synthetic, oxidative, reductive, or splitting powers of various tissues and organs have been brought to light. In this way, too, intermediate products of metabolism are discovered and glimpses of hidden chemical processes are obtained which throw light on deep problems of pathology and clinical medicine. The results of the study of the relation of chemical constitution to physiological action as yet apply only to certain families of chemicals. They have not led to any principles of universal application. Recently a clearer statement of the action of whole series of drugs and poisons has been given in the language of physical chemistry. Thus, this or that feature of the pharmacologic action of many acids is in proportion to the concentration of their hydrogen ions and depends to a lesser degree on the specific properties of their anions. The toxic or disinfecting action of a series of dilute metal hydroxides stands in relation to the concentration of the $\mathrm{OH}$ ions. The theory of electro- 
lytic dissociation, on the other hand, plays but a subordinate part in determining the toxic properties of phenylic and other compounds. But whenever this theory is applicable to the problems of our science, it has put them in a new light. Yet it must be remembered that when we say the pharmacologic action in a given case is ionic, we are still far from the last possible analysis and explanation of the observed phenomena.

A new epoch began with the belief that many diseases are but instances of acute or chronic intoxication. The growth of the doctrine of toxins forced upon us by modern experimentation in bacteriology is seen in pharmacological literature and methods. The recent studies in the action of toxins and antitoxins, on the nature of immunity, on the nature and cause of diabetic coma, uremic poisoning, and other pathologic conditions in which poisons generated within the body play a role, are all instances of researches in which repeated use of pharmacologic methods and principles is made. It is evident, then, that pharmacology deals with the most fundamental conceptions of medicine, that it conserves and augments a variety of facts, methods and principles which are of service not alone to every branch of the medical art, but also to other branches whose subject-matter confines them to the laboratory, the private study, and the lecture hall.

When and how shall this subject be taught in our medical schools?

First, as to the time when it should be taught. I hold that this should be when the student begins his clinical studies and not before. I do not deny that it is often difficult to make room for this subject in the first clinical year, but the argument which in reality excludes it is that pharmacology, like physiology, is so capable of illustration by laboratory experiments and of presentation in the form of lecturers, that it can be taught as soon as the student has the needful foundation in the way of physiologic chemistry, anatomy and physiology.

But this argument ignores the fact that every drug has its clinical uses, that the teacher of pharmacology is expected to point out what these uses are, and that it is impossible to avoid reference to diseases and their symptoms. In the interest of the student, by way of lightening his work and making it more profitable to him, it is imperative to teach pharmacology hand in hand with the early clinical work. For now he begins to see drugs used; he notes, for example, how a patient behaves under ether; for what conditions the clinician prescribes iron, quinin, mercury, salicylic acid, codein, digitalis, potassium iodid, amyl nitrite and the like; what antiseptics and local an62 
esthetics are used by the surgeon. He perhaps sees an outpatient with a gangrenous finger due to his having swathed it in $5 \%$ carbolic acid; he learns of mercurial stomatitis, of palsies and neuritic affections and anemias caused by the heavy metals, of exanthems due to drugs; he sees examples of iodism, cinchonism, etc., and specimens of urine that show misleading features in consequence of certain drugs. Though only a beginner, he meets at every turn with some practical application of the articles of our materia medica. Drugs now have some significance for him, an interest is aroused in their action, important data and conceptions are gathered by actual experience.

It must be remembered, too, that a description of the symptoms that appear when more than the therapeutic dose of a drug is given is an integral part of the teaching of the pharmacologist. In a word, toxicology is inseparable from pharmacology, and instruction in this branch, so far as it is not of a chemical or medicolegal character, deals with clinical and pathological data. How wasteful of energy is it to teach this part of the subject at a time when all practical knowledge of such data, with the exception of that gained by experiments on animals, is lacking! What does the student profit from descriptions, for example, of the nature of cocain, atropin, opium, or arsenical poisoning, at a time when he has seen nothing whatever of bedside medicine?

To say that the practical examples of the uses of drugs and of their toxic action can be as well learned by the student after he has taken the course in pharmacology is to deny the principle of economy in intellectual work, and indicates a lack of appreciation of the fact that the applied and the theoretical parts of pharmacology are not capable of a sharp separation in courses intended for medical students.

The question as to how we shall teach pharmacology may now be considered. But first, a few words concerning instruction in toxicology. It has already been stated that, from a scientific point of view, no sharp line of demarcation can be drawn between this subject and pharmacology. Only when the medicolegal, the industrial, or the chemical sides of toxicology are considered is it advisable to make a distinction. But these aspects of toxicology should not be neglected in our medical schools. Even in institutions in which the general principles and methods of toxicological analysis are taught in connection with the work in chemistry, or in which extensive courses in legal medicine and in hygiene are given, there will still be left a large field to be covered by the pharmacologist. In my own experience I have found it advantageous to give a brief course in toxicology as a pre- 
liminary to the work in pharmacology. My students begin their work with me at the conclusion of the first third of their second year, at a time, therefore, when they have had no clinical work and but little pathology. The course requires eight weeks, and there are two afternoon sessions and a Saturday morning recitation or conference. The points aimed at in the course are: First, the acquisition and comprehension of the physiological phenomena of intoxications; second, certain important phases of the subject regarded as a part of forensic medicine; third, the more important chronic intoxications which are met with in the arts and industries; and fourth, the general principles of toxicological analysis as illustrated by actual practice at the laboratory desk.

Nothing in the way of vivisection is done by the student himself in this course.

The afternoon's work begins with a brief lecture and with demonstrations of a physiological character. In these a number of circumstances bearing on the action of a given substance, whether used as a poison or as a drug, are clearly set forth. These demonstrations constitute the best introduction to pharmacology. Some of the points illustrated are the varied symptoms of poisoning, such, for example, as the paralysis of the respiratory center by hydrocyanic acid or morphin; the influence of the place of application, as illustrated by the fact that not all mucous surfaces absorb poisons with equal rapidity; the rapidity of dispersion of poisons throughout the body; the paths of elimination for drugs and poisons, and the storage of drugs in various tissues and organs, and the great differences that obtain in these two fields; changes in the blood; the anatomical lesions produced by powerful poisons, such as arsenic, phosphorus, nitric acid, carbolic acid, alkalies, etc. A wide range of demonstrations, in which organisms ranging from paramecia to dogs and rabbits may be employed, is at the disposal of the instructor, who has access to original literature. In this way the beginner receives ocular proof of the fact that an intoxication, whether acute or chronic, is as complex a matter as any of the clinical conditions that he will later study in the hospital; that drugs can produce fever, convulsions, paralysis, and other symptoms; lesions of the various organs, alterations of the secretions and of the blood-in short, an interest in the manifold problems of medicine can here be aroused. It is, of course, understood that the rules of the physiological laboratory in regard to anesthesia are to be observed in work of the above character. During the first week of this course the demonstrations extend so far into the afternoon that the 
student has no time left for laboratory work, and can only arrange his desk for the chemical work.

The chemical work of the student is so planned that it shall instruct him in certain methods which will be of use to him in his later work in clinical medicine and will enable him also to make at least the necessary preliminary tests in a case of suspected poisoning. A small laboratory manual drawn up by the instructor is placed in his hands and its directions are modified from year to year. The ground covered in the laboratory includes the methods of isolating volatile poisons and the analytical methods applicable to the detection of small quantities of this class of poisons; the search for alkaloids and glucosids by the methods of Draggendorff, Brouardel, Kippenberger, and others, some typical poisons of these classes being mixed with foods and subjected by the student to processes suitable to their extraction; the search for metallic poisons and non-volatile acids; a study of blood-stains and the separation of blood from rust-spots, etc.; a spectroscopic and simple chemical study of the various hemoglobin derivatives as methemglobin, hematin, reduced hematin, hematoporphyrin, carbon monoxid hemoglobin, etc.; a study of the changes in the urine induced by drugs.

In a course of this kind a wise selection of examples must be made and assistance must be given to the student by means of class demonstrations and informal talks, as well as by instruction at the laboratory desk.

In the past few years our students have come to us with a better preparation in chemistry, and many of them have already had a special course in the detection of metallic and other poisons.

To avoid repetition we have therefore arranged a few class demonstrations showing the best methods of oxidizing organic matter and of detecting arsenic, antimony, lead, mercury, and phosphorus, paying especial attention to the simpler preliminary tests which shall enable the physician, if need be, to ascertain with certainty whether one or another of these poisons is present. The object of this chemical course is, therefore, mainly to give the student a bird's-eye view of the field, with a certain technic of an elementary sort and to further improve his chemical knowledge, something for which the modern physician finds more and more practical uses. Should the student who has taken such a course ever find himself involved as a medical expert in a medicolegal case he will not be entirely incapable of comprehending the controversial points which are agitating the chemical experts in the trial. 
Along with this chemical work goes the reading of selected chapters of a good textbook, recitations, and informal talks by the instructor on special subjects, as the commoner poisonous plants of the country, or the intoxications met in the modern arts and industries. The talk or the recitation, as the case may be, is held early in the afternoon, before the laboratory work is begun. An hour on one other day on which no laboratory work is done is also given up to a recitation on assigned subjects.

It will be seen that there is little in the way of didactic lectures. The student profits most when, for example, he has himself detected opium in some mixture and has read his Blyth, Kobert or Lewin and then meets his instructor, to discuss with him, in an informal manner, the chief points in the physiologic action of the poison in its chronic use, or in its medicolegal significance and chemical detection. His previous reading has aroused his interest, and taken in connection with his chemical experiments and the demonstration on the living animal, it has prepared him for a conference whose chief aim is to help him to separate the essentials from the nonessentials.

The remainder of the year is devoted to pharmacology. This course is only in part a laboratory course, the class working in sections of four. Even if it is impossible for the student to perform more than a half-dozen experiments, this kind of work is too valuable to be omitted. Nowadays, when simple apparatus can be had at a comparatively low cost, it is not a matter of great difficulty to give every four students out of a class of 75 a number of highly instructive experiments. These may be so arranged that the student himself learns the chief pharmacological facts involved, say, in the action of ether and chloroform, the diuretics and purgatives, atropin, morphin and chloral, or digitalis, the nitrites and other agents that have a pronounced action on the circulatory apparatus.

I would, therefore, urge that at least 5 or 6 topics be made the subject of laboratory experiments to be preformed by the students themselves under competent direction. The "artifically contrived experiment" has made the subject what it is; it is that instrument of knowledge with which the teacher and investigator tests the theories of the day; it is his very shortest road to certainty of opinion. Why, then, should it not give a clearer insight to the student also? As Porter so tersely puts it, "the meat on which professors are nourished is just the diet for students."

As for the rest of the experimental work, numerous class demonstrations are necessary. The work in physiology, perhaps going on at 66 
the same time, has prepared the student to grasp the principles to be illustrated by the more complicated experiments and perhaps also made it unneccessary for the student himself to perform the many simple experiments to which he is equal, but which can be more quickly performed for him. For we must keep in mind that as Professor Welch has said, "Laboratory methods are extremely time-taking and are not adapted to teach the whole contents of any of the medical sciences." I need not recount the list of practicable class demonstrations. There is hardly a drug of importance for which a good demonstration is not to be found in the various scientific journals. We know that the list of drugs in actual use is very large, but if we ask what are those that have been found to be really indispensable to the surgeon, the gynecologist and obstetrician, the internist, the ophthalmologist, dermatologist and other specialists, we can easily reduce our portentous list to some fifty instances. Let these constitute the basis of instruction and serve as types; take these up in great detail, and whenever possible connect with them less important ones of similar action.

But to assist the student to master the contents of his particular subject should not be the only aim of the medical teacher; he should seek to arouse an appetite for all that is fundamental in the science of medicine; he should stimulate to inquiry, to a searching and logical analysis of the phenomena to be grappled with, be it in the laboratory or at the bedside. And in striving to carry out this high purpose, his own life work, his spoken words and his attitude toward his pupils are his chief means of influence.

I have thus far said nothing on the subject of Materia Medica. I do not believe that special instruction in this branch is called for. In the day when the student to the medical school entered with little knowledge of chemistry, botany, and other sciences, it may have been well enough to give special courses on the physical, chemical, and botanical characteristics of drugs, but the result in general was to overburden the student's mind with a multitude of dry details of interest or value solely to the pharmacist or to the student of pharmacognosy. When I began to teach pharmacology ten years ago, I discarded all separate instruction in materia medica. My plan has been to give only those points which are of actual importance to the student of medicine or which he ought to know for historical reasons. The drugs and preparations which are discussed in lectures and recitations are placed on a table where all may examine them, and the more important ones are passed from hand to hand while they are being described. In speaking, for example, of rhubarb, digitalis, cinchona, 
ergot, or opium, only brief historical remarks, with short accounts of their chemical composition and their behavior toward solvents are introduced.

Certainly all unnecessarily detailed description of crude drugs, of their active principles, or of the modern synthetic remedies, is out of place in a medical school. The instructor should allow himself but the briefest introduction as to the physical and chemical properties of a drug before he begins the more important discussion of its pharmacological action. Thus, when chloral is the subject, he will describe its chemical relationship to the other anesthetics and hypnotics, its solubilities, its deliquescence, its decomposability by alkalies, etc. A rapidly-performed test-tube experiment showing how chloroform is split off when it is brought into contact with an alkali will prevent the student from prescribing it in this form. Such a method of treatment consumes but little time and is easily comprehended by the student who has had a suitable preliminary course in chemistry. In a word, I would teach materia medica in direct connection with pharmacology, letting it serve in the case of each drug or class of drugs as a brief introduction to the latter and giving only such parts as are indispensable to the physician in his administration of drugs or of such historical significance that they ought not to be neglected from the culture point of view. Here, as everywhere in our crowded courses, wise selection is our only safeguard. With regard to the pharmacopeial preparations it has always been my plan to require only a knowledge of the more important ones, the student being requested merely to read over those of lesser importance. There is much truth in the renark made by William Withering more than a century ago, that "the ingenuity of man has ever been fond of exerting itself to vary the forms and combinations of medicines. Hence we have spirituous, vinous, and acetous tinctures; extracts hard and soft, syrups with sugar or honey, etc., but the more we multiply the form of any medicine the longer we shall be in ascertaining the real dose."

Certain chemical and physical points which have a bearing on the combination of drugs as called for in prescriptions, or official preparations may be taken up again in a brief course in pharmacy. I cannot believe that the art of preparing drugs for therapeutic use requires a prominent place in the better medical schools of the day. The young physician who is fairly well trained in chemistry can get all that is necessary in the way of pharmacy out of a course of at most a dozen or fifteen lectures in which systems of weights and measures, incompatibles, and special points relating to prescriptions are dealt with, 
and in which demonstrations are given of how pills, tablets, suppositories, tinctures, and other official preparations are prepared.

In schools where the student is admitted with but a poor elementary training much more than this may be necessary. But, even under the most favorable conditions the limited course above outlined will leave much to be desired, even then the physician is not ensured against the commission of grave errors in prescribing. Without further study he must often rely upon the friendly hand of the professional pharmacist to correct his mistakes.

Here, too, then, the question is one of selection, of just how much will suffice in a field which is occupied by an allied profession.

There are great differences of opinion in regard to instruction in Therapeutics. In teaching pharmacology the therapeutic uses of drugs must necessarily be considered in more or less detail and pharmacological discoveries harmonized whenever possible with clinical practice. It is, therefore, necessary that the teacher of pharmocology shall be familiar with clinical work and with the actual effect of drugs and poisons on human beings. It is not necessary, however, that he should be an active practitioner, and it is only a man of unusual powers and exceptional training in science who can successfully combine practice with the demands made on the pharmacologist of the present day as an investigator and a teacher. In all the leading universities of the world it is becoming more and more the custom for teachers of physiology, anatomy, pathology, physiological chemistry, and hygiene to devote themselves wholly to the duties of their chairs, and this practice will prevail more and more among pharmacologists as the wealth of medical foundations increases. No one individual, even if he has the widest clinical experience, can hope to teach the whole art of therapeutics. Is it necessary to attempt this? Is not the clinical teacher who is well grounded in the fundamental sciences the only one who can rightly train the medical student in the correct choice of drugs and other agents whose employment falls within his province?

Who, for example, can better teach the student how to treat the various acute and chronic forms of skin disease than the dermatologist; who better to treat the diseases of young children than the pediatrist; who better the details of drug application in diseases of the eye, throat, and nose than the specialist in these branches; who give wiser counsel in the use of drugs, foods, and other agents in the wide field of the internist than he who daily grapples with difficult problems in the cure and alleviation of disease? A practical mastery of therapeutics can only be obtained from contact with these men and their work. 
In a limited way, a special course in practical therapeutics in the field of internal medicine may be given in a medical school, and it is of great assistance to the medical student who is obliged to enter upon practice immediately and without the advantages to be derived from a year or two of hospital practice. A course of this kind is a part of the curriculum of the Johns Hopkins Medical School and is given by an instructor in clinical medicine. It occupies a period of 15 weeks and consists of lectures and demonstrations given twice a week; as stated in the announcement of the gentleman in charge, this course comprises the clinical study of a number of the more common and useful drugs, their dosage, administration, and effects, methods of prescription-writing and illustrative formula, demonstrations of practical therapeutic measures, the use of liydrotherapy, the preparation of simple and useful forms of diet, the care of patients considered from the nursing point of view, the treatment of various emergencies and of special diseases by climate, rest, and other practical procedures.

The clinical work of the third and fourth years affords abundant opportunities for further training in practical therapeutics.

This brings me to the subject of lectures and recitations or conferences.

Some didactic teaching, be it in the form of lectures, recitations or conferences, is necessary in most, if not all, branches of medicine. In these exercises, the teacher not only clears up doubtful points and summarizes scientific evidence, but he also has an opportunity to so direct "the unwary understanding" of the young, as Sir Thomas Browne has it, that some perchance will escape intellectual sclerosis at forty.

My own experience with students has led me to believe that they profit most if they have first read their textbooks before attending a lecture on a given subject. The teacher's own experience is that he derives most advantage from a consultation with a specialist in some other branch of science when he has first informed himself on the points at issue. It is then that a short talk with a man of wide experience easily clears up an obscure point. The student should be put into a similar attitude of mind by proving to him that he will get more out of an hour with his teacher than out of an hour with his books at home. If the subject under discussion is one that is well treated in textbooks, the established points may be passed in rapid review and then the latest researches, the newer theories brought out by the instructor. Whenever it is possible to do so, demonstrations and experiments should be used to illustrate the points under discussion, and these may be given either during the talk or immediately after. 
No matter how well a textbook may be written, the teacher who is himself a worker in the laboratory and who follows attentively the researches of his contemporaries, will be able to clear up doubtful points and also to daily anticipate the author's second edition, for the last chapter of a textbook is hardly completed before the first needs revision. Aside from this, he is likely to have the advantage of the author of the book in certain fields, for no man is able to cover the whole ground with equal authority.

Now as to the student's part. I hold that only the laboratory work and attendance on such demonstrations as are of the highest importance should be obligatory. With such attendance and diligent reading of the best textbooks on the subject, the student will be able to bring himself up to the "pass" mark, since the examination should only cover the essential points, aiming like the later State examination to test and insure an average of attainment and an ability to make use of acquired knowledge. Of course the student will not in this way get the utmost possible out of the course, but to do this may not be a part of his plan of study.

He should be plainly told that he need not attend the lectures and recitations unless convinced that he will profit by them, and the head of the department and his corps of assistants will surely be above any small resentment when the student accepts this permission in good faith. The mutual attitude of teacher and student is of far more importance than rigidity of examinations or any tests or credentials whatever. I firmly believe in the liberty of both teacher and student. It is but fair to require of the former that he be a worker in some part of his field, and that he shall meet with enthusiasm and give his best to those who elect to go deeply into the subject as well as to do his duty to those who choose only the minimum or required work.

The immediate result of this frank understanding between teacher and student will be that the latter is free to give additional time and energy to some other line of work for which he may have a decided bent. But much more, he has the freedom of personal choice, with all the development that it brings to one who understands his orn mental habits and needs. Petty and irritating restraints are removed and also the undue weight of authority sometimes attached to a curriculum supposed to be the result of the wisest judgment of his elders. We are apt to forget that we are dealing with men and women of some maturity whose plan for their life-work is made and who have a clear idea in general, of what their time is worth. They should have, as Bowditch, Mall, and other writers on this subject have pointed out, 
the advantages of an elective system and also, I maintain, have some freedom as to method of work in the field chosen.

Have childish restrictions, such as marking for daily attendance, and all the hateful machinery of the factory time-card system, by which some teachers attempt diurnal estimates of the student's mental status, resulted in such a remarkable elevation of the average student, that we should cling blindly to our present system?

As to examinations, that "necessary evil," I believe it will be admitted that, in subjects like that now under discussion, they should not be conducted as if the student were intending to make a specialty of each branch. They must be fair to the class as a whole. In my own opinion, a combination of written and oral insures the best results. Personal knowledge of the student's laboratory work, and also of the intelligence shown by him in recitations, is of great importance in enabling the instructor to judge of a student's right to his pass certificate. The ideal examiner for a given student is not always the man who has taught him, but may well be a specialist of equal rank in some other university. Such a change, so stimulating to the intellectual independence of the student, and so broadening to the teacher, could only be based on a better agreement than now exists in our country as to the teaching of a given branch in schools of equal grade. As long as faculties issue diplomas, they assume a responsibility toward the world of learning. How they shall discharge this duty is too large a subject for full discussion here, but it is very desirable that the method used shall involve a minimum of worry and strain on the part of the student, and of police duty on the part of the teacher. 


\title{
On the Removal of Diffusible Substances from the Circulating Blood by Means of Dialysis
}

\author{
JOHN J. ABEL, M.D., L. G. ROWNTREE, M.D., AND
}

B. B. TURNER, M.D.

$\mathrm{T}$

HERE are numerous toxic states in which the eliminating organs of the body, more especially the kidneys, are incapable of removing from the body, at an adequate rate, the natural or unnatural substances whose accumulation is detrimental to life. In the hope of providing a substitute in such emergencies, which might tide over a dangerous crisis, as well as for the important information which it might be expected to provide, concerning the substances normally present in the blood, and also for the light that might thus be thrown on intermediary stages of metabolism, a method has been devised by which the blood of a living animal may be submitted to dialysis outside the body, and again returned to the natural circulation without exposure to air, infection by microorganisms, or any alteration which would necessarily be prejudicial to life. The process may be appropriately referred to as "vividiffusion."

Essentially, the method consists in passing the blood of an animal which has been made incoagulable in injection of hirudin from a cannula connected to an artery through a tube or a series of tubes, made of celloidin or other suitable dialyzing membrane, contained in a jacket filled with a saline solution or artificial serum, and back by another cannula into a vein of the same animal. The tubes and cannulae before connection are filled with a saline solution approximating to the composition of the blood, like Locke's or Ringer's solutions, which is displaced into the system when the circulation is established. Except that the blood-pressure falls somewhat, according to the proportion of the blood outside the body, the animal shows no immediate symptoms, and with due regard to asepsis, makes a rapid and complete recovery after an experiment that may last several hours. 
In one instance, where recovery was not aimed at, a dog anesthetized with chloretone was kept alive during a dialyzing period of sixteen hours with about one-third of its blood outside the body. At the end of an experiment the larger proportion of the blood in the apparatus may be driven back into the body by air-pressure or by means of a saline solution which is allowed to flow into the dialyzing tubes from a higher level and which thus drives the blood ahead of it into the body.

Many experiments have been made to determine the best form of apparatus combining maximum diffusing surface with minimum volume, absolute freedom from leaks, ease of construction, uniformity of flow, minimum exposures to surfaces of glass or other substance liable to favor clotting, etc. The most efficient type in use at present has thirty-two celloidin tubes of $8 \mathrm{~mm}$. diameter, $40 \mathrm{~cm}$. long, fastened by tying with a string to a system of glass tubes branching dichotomously, so that the flow of blood takes place horizontally twice in each direction through eight tubes in parallel. (An apparatus of this size can only be attached to animals of at least fifty pounds' weight.) Flattened tubes and other types are being tried, while very small tubes will undoubtedly prove valuable when the necessary time and trouble are not prohibitive. [See illustration between pages 16 and 17.]

Such an apparatus can obviously be used in the solution of many problems, both therapeutic and physiological, and is especially valuable in the latter case because, apart from the necessary anesthetic, the normal physiological condition is in nowise disturbed, as by bleeding to obtain large amounts of blood. Diffusible substances, present in only small proportion at one time, may be isolated in considerable quantities provided they are regenerated in the body as fast as they are removed. Evidence of this has already been obtained in the case of the dialyzable (non-proteid) nitrogen which is extracted in large quantities in prolonged experiments. Determinations by Van Slyke's method have shown a high proportion of nitrogen in the form of amino groups $\left(\mathrm{NH}_{2}\right)$, and experiments are in progress for the isolation of individual amino-acids by Fischer's esterification method. Several grams of the esters have been obtained by distillation in a vacuum of 1 to $16 \mathrm{~mm}$. at temperatures from $70^{\circ}$ to $180^{\circ} \mathrm{C}$. Bases precipitated by phosphotungstic acid have also been obtained, but they apparently constitute a more complex mixture than those usually obtained in the digestion of proteins by acids, and the discovery of new bodies, possibly including polypeptids, seems probable.

Quantitative data have been obtained with a view to comparing the 74 
efficiency of the apparatus in the elimination of poisons with the natural kidney. Administering to a rabbit 1 gram of sodium salicylate, an extraction as rapid as 3 per cent in one-half hour has been observed, which compares very favorably with the normal action of the kidneys; in the case of a dog with the same dose, using another apparatus, 4 per cent was obtained in the first hour and a total of about 20 per cent in sixteen hours. Better results may be confidently expected with an apparatus having more surface in proportion to the volume. Potassium iodide also passes through the membrane readily as does phenolsulphonphthalein. Of the substances naturally present in the body, sugar, phosphates, diastase and other substances diffuse in notable amount.

Ethyl sulphide, $\left(\mathrm{C}_{2 .} \mathrm{H}_{5}\right)_{2} \mathrm{~S}$, which is so readily evolved from dogs' urine on the addition of lime-water or other alkali, may be obtained in like manner from the diffusate, showing that the mother-substance of this malodorous compound is freely eliminated by our apparatus.

A wide field of investigation is opened up by the use of this apparatus in a comparative study of the blood flowing to and from various organs with reference both to the substances which they extract from, or add to, the general circulation and to the special active principles (hormones, etc.) which may be present in their internal secretions. A beginning in this direction has been made by attaching the apparatus to the portal vein, (four experiments), the blood of which gave by diffusion considerably more amino-acids (determined by Van Slyke's method) than that of the carotid. Work in this direction, as well as in the improvement of the apparatus for the various purposes above outlined and accumulation of the experience necessary along these lines, is being pushed actively forward. A full description of the apparatus, with directions for its use, togethier with the results, will appear in the January number (1914) of the Journal of Pharmacology and Experimental Therapeutics. 


\section{Crystalline Insulin}

JOHN J. ABEL, M.D.

I

Two preceding communications, ${ }^{1,2}$ it has been told how my collaborators and I were induced to attack the problem of the isolation of insulin and what progress had been made toward its solution to within a few months past. It was there pointed out that a clue had been found, the following out of which promised to lead to the desired goal. This clue eventuated from the observation that when the highly impure and complex, though therapeutically serviceable insulin extracts of commerce are boiled for a short time with $N / 10$ sodium carbonate the resulting physiological inactivation of the extracts is always associated with an alteration of a part of their sulphur, an element which our experiments justified us in believing to be an integral constituent of the hormone itself. After such treatment with a weak alkali a new property appears in the altered insulin in that it now shows an extraordinary sensitivity to very dilute acids which immediately, and contrary to their usual action, liberate hydrogen sulphide from it. It was found that inert fractions prepared from such extracts of the pancreas contain very little of this labile sulphur and a table was constructed which showed that the labile sulphur of a preparation is directly proportional to its hypoglycaemic activity for experimental animals. In other words, the higher the amount of labile sulphur in a given preparation the greater its potency in lowering the percentage of blood sugar.

The methods usually employed in fractioning and purifying biological mixtures have been found to be quite useless in the attempt to separate the hormone from the numerous impurities that are associated with it in even the best of the extracts employed in medical practice. Equally unsuitable to the purpose in mind was the employment of the method of isoelectric precipitation from $\mathrm{pH} 4.7$ to 5.0 no matter how frequently repeated, as likewise the analogous method of electro-dialysis-a method which has not yielded results of any particular value in the hands of those who have tried it out on insulin extracts. We are here dealing with an ampholyte present in very small 76 
amount in a solution of other ampholytes whose solubility and precipitation coefficients lie very close to one another. It seemed worth while to the writer therefore to employ only weak bases and acids, more especially such as can act as buffers, in the hope that there might result from their use such an alteration of solubilities, that impurities would either fall out of or remain in solution while the hormone in each case took the opposite course. The successful outcome of the experiments proved the essential correctness of the idea.

For a description of our earlier methods of purification the reader is referred to the first paper of this series. The employment of the simple method there described, led uniformly to the preparation of an insulin fraction, Fraction IV, with a rabbit unitage of 40 or more units to the milligram, a unitage that has lately been increased by a more skilful use of these earlier methods. The next steps in the process leading directly to the crystallization of insulin are as follows.

One gram, approximately, of the so-called Fraction IV, is dissolved in a little more than the required volume of $N / 6$ acetic acid, enough water is added to bring the volume up to $60 \mathrm{cc}$. or thereabout, and the contaminating substances (together with some insulin) are then precipitated by the addition of an acidulated solution of brucine containing 6 gms. of brucine in $95 \mathrm{cc}$. of $N / 6$ acetic acid. The resulting clear supernatant fluid which contains nearly pure insulin is separated from the precipitate by centrifugalization. Insulin remaining in the precipitate may be removed by dissolving in $N / 6$ acetic acid and precipitating with the brucine solution as before. How profitable it may be to repeat the process has not been determined at the moment. The clear colorless centrifugalate containing the insulin is then pre. cipitated with $N / 6$ pyridine and the precipitate and fluid are immediately centrifuged. The precipitate which settles out is largely crystalline in character, the sides of the tube are found to be coated with glistening highly refractive crystals and the topmost layer of the precipitate consists of similar crystals. It is not a difficult matter to remove this topmost layer of crystals by means of a rubber-mounted pipette and to free them from adherent pyridine and acetic acid by frequently washing them with distilled water at room temperature in which medium pure crystalline insulin is quite insoluble. The crystals may be recrystallized by dissolving them in $N / 6$ acetic acid and reprecipitating with $N / 6$ pyridine. It has been my practice, however, of late to dissolve this crystalline insulin together with whatever fine granula1 material there happens to be mixed with it in $M / 15$ disodium hydrogen phosphate. To the clear solution $N / 6$ acetic acid is added drop by 
drop with vigorous shaking in order that any insulin thrown out will at once pass into solution again, and this addition of the acid is continued until a slight amount of turbidity persists permanently. The flask is then carefully set aside overnight. On the following morning the bottom of the flask as well as its sides are coated with an abundance of colorless, highly refractive crystals. The small amount of amorphous insulin that falls out in very minute granules or floccules-an expression of the above-mentioned turbidity-is readily separated by means of the pipette during the washing with cold water, as the compact crystals obtained by this method sink quickly to the bottom of the tube like so much sea sand. This process of crystallization may be repeated as often as is thought to be necessary. Only a few experiments have as yet been made with the object of crystallizing the compound from lot solvents, and to prepare crystalline derivatives.

Professor Swartz of the Department of Geology of the Johns Hopkins University has kindly examined samples of the insulin crystals and reports them as being very uniform in character suggesting a high degree of purity, as doubly refracting and as belonging to the rhombohedral division of the hexagonal system. [See illustration between pages 16 and 17.] The crystals which are allowed to form more slowly out of acidulated disodium hydrogen phosphate solution are very much larger than those precipitated quickly by pyridine out of an acetic acid solution, such crystals being readily perceptible to the naked eye as individual crystals. Irrespective of the manner of their preparation the crystals melt sharply at $233^{\circ} \mathrm{C}$. with slight browning occurring at $215^{\circ} \mathrm{C}$. The melting point lias remained constant on recrystallization.

Chemical Reactions.-A large fraction of the sulphur of the molecule is in the labile state previously described as characteristic of all insulin fractions of high rabbit unitage. Quantitative analyses of both the labile and more firmly bound sulphur are in progress. The compound gives a beautiful biuret reaction passing from a clear pink to a fine purple on further addition of copper sulphate to the alkaline solution. Millon's reaction is unequivocal and positive. The Pauly and the ninhydrin reactions are also positive. This pure insulin is very sensitive to alkali, as shown by the fact that boiling for 15 minutes with $N / 10$ sodium carbonate deprives it entirely of its hypoglycaemic activity. It will be seen that the chemical reactions here described are of considerable significance as shedding light on the chemical structure of the compound. It is now being examined in respect to its other 
pliysical and chemical properties and efforts will also be made to identify its various cleavage products.

Animal Experiments.-Numerous tests have already been made in order to establish the exact rabbit unitage of the crystalline compound. The rabbit unit employed by us is that fraction of a milligram per kilogram of body weight which will cause convulsions or lower the blood sugar to 0.045 per cent within 5 hours. This corresponds to approximately $11 / 2$ times the "clinical unit" used at present.

The exact dosage of the crystalline material has not yet been established, but for the present, as is shown in the subjoined table (1), amounts as small as $1 / 100$ of a milligram per kilo lowered the blood

TABLE 1

Blood Sugar Determinations

Insulin crystals dissolved in $\mathrm{M} / 15 \mathrm{Na}_{2} \mathrm{HPO}_{4}$.

$1 \mathrm{mgm}$. equivalent to $10 \mathrm{cc}$. solution.

Injections were made subcutaneously.

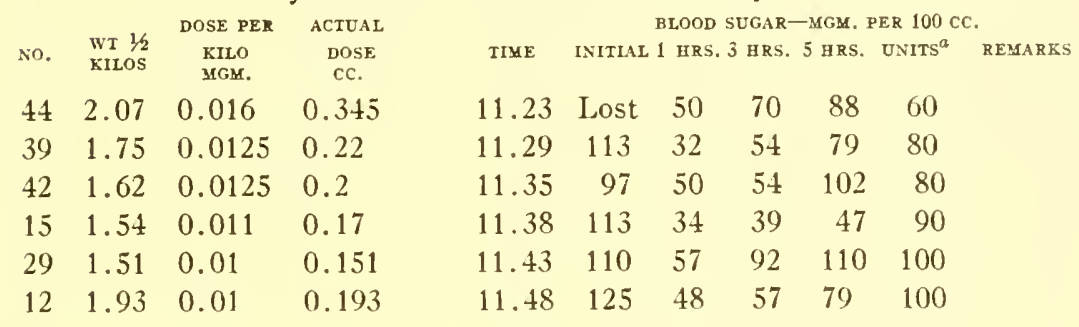

TABLE 2

$\begin{array}{lllllllllll}14 & 1.6 & 0.008 & 0.13 & 11.06 & 119 & 25 & \ldots & \ldots & 125 & \text { Convulsion } \\ 46 & 1.95 & 0.008 & 0.15 & 11.11 & 115 & 56 & 77 & 111 & 125 & \end{array}$

${ }^{a}$ As defined in the text.

sugar to about the convulsive level, 0.045 per cent. In another series of experiments $1 / 125$ of a milligram per kilo produced convulsions in one rabbit and lowered the blood sugar almost to the convulsive level in a second animal. (Table 2.) It will be clear, therefore, that we are dealing here with a hormone which, in very high dilution, influences carbohydrate metabolism acting as it were like a catalyst in a chemical reaction.

With the isolation of this hormone in crystalline form we are leaving the region of qualitative experiments, and may look forward to quantitative results both in the biological and chemical field which the future promises to yield. 
My collaborators in this field of work, Dr. E. M. K. Geiling, Dr. C. A. Rouiller and Dr. David Campbell and I hope to be able in due season to publish more extensive reports on the various researches which naturally arise in the investigation of the properties, chemical and biological, of the pure product.

${ }^{1}$ Abel, J. J., and Geiling, E. M. K., Jour. Pharm, and Exper. Therap., 25, 423, 1925.

${ }^{2}$ Abel, J. J., Geiling, E. M. K., Alles, G., and Raymond, A., Science, 67, 169, 1925. 
. 



\section{,}




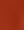
$\therefore \quad 10$

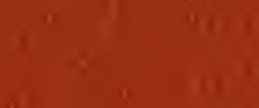

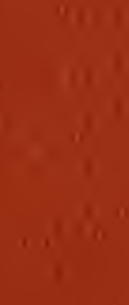

ton 